CAIMI FRANCO REIS

\title{
GENERALIZAÇÃO DO CAPM APLICADA AO CÁLCULO DO CUSTO DE CAPITAL DO SETOR DE TELEFONIA FIXA DO BRASIL
}

Dissertação apresentada à Escola Politécnica da Universidade de São Paulo para obtenção do título de Mestre em Engenharia. 
CAIMI FRANCO REIS

\section{GENERALIZAÇÃO DO CAPM APLICADA AO CÁLCULO DO CUSTO DE CAPITAL DO SETOR DE TELEFONIA FIXA DO BRASIL}

Dissertação apresentada à Escola Politécnica da Universidade de São Paulo para obtenção do título de Mestre em Engenharia.

Área de concentração:

Engenharia de Sistemas

Orientador:

Prof. Dr. Oswaldo L.V. Costa

São Paulo

2006 
FICHA CATALOGRÁFICA

\section{Reis, Caimi Franco}

Generalização do CAPM aplicada ao cálculo do custo de capital do setor de telefonia fixa do Brasil / C.F. Reis. -- São Paulo, 2006.

89 p.

Dissertação (Mestrado) - Escola Politécnica da Universidade de São Paulo. Departamento de Engenharia de Telecomunicações e Controle.

1.Telefonia (Aspectos econômicos; Avaliação) - Brasil I.Universidade de São Paulo. Escola Politécnica. Departamento de Engenharia de Telecomunicações e Controle Il.t. 
Aos meus pais pelo amor, sacrificio e carinho de sempre 


\section{Agradecimentos}

Ao Prof. Dr. Oswaldo Luiz do Valle Costa pela disponibilidade e atenção.

Ao Dr. Everaldo Gomes Ferreira, Dr. Marcondes de Oliveira Buarque e Dr. Francisco Montoni Júnior pelo constante incentivo.

Aos meus irmãos Caio e Ciro pelo constante interesse.

Aos meus sobrinhos João Vitor e Caio Vinícius pelo estímulo.

A todos os meus colegas de trabalho, em especial, Aldo, Francisco Luis, Renato e Ronaldo pelo interesse e pelas dicas oportunas.

A todos os demais amigos e colegas pelas discretas contribuições que ajudaram a engrandecer este trabalho.

À Escola Politécnica da Universidade de São Paulo pela oportunidade.

À Anatel pela concessão de horário especial. 
"Faz mais aquele que quer do que aquele que pode." 


\section{SUMÁRIO}

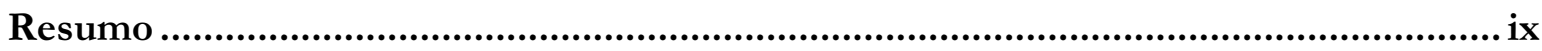

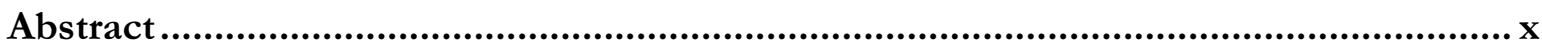

Lista de Ilustrações................................................................................................... xi

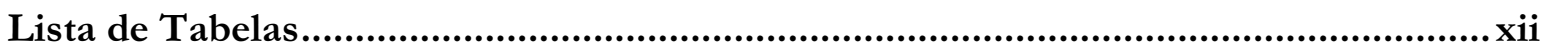

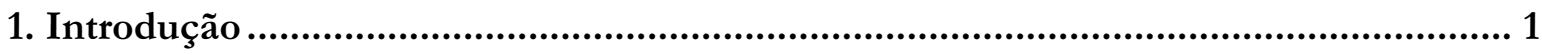

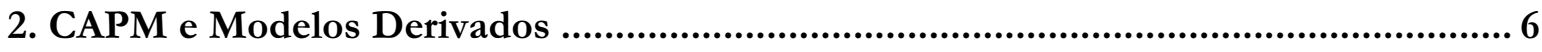

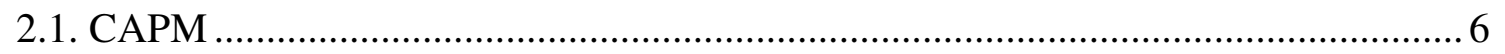

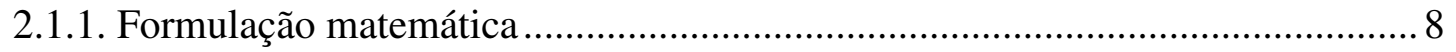

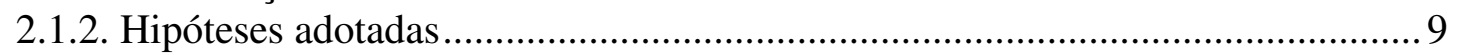

2.1.3. Problemas na mensuração do Beta ................................................................... 9

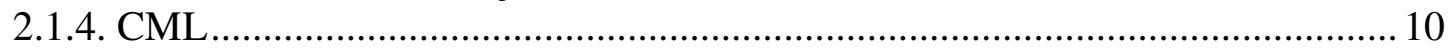

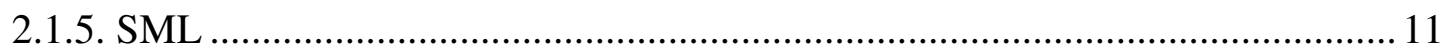

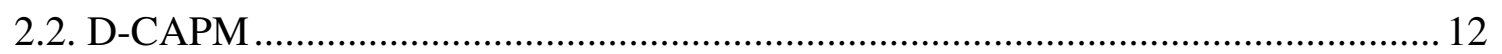

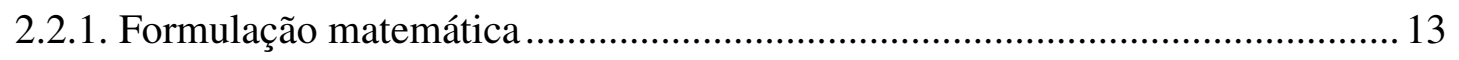

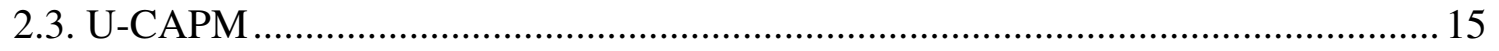

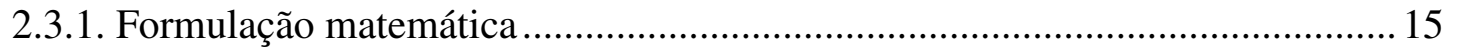

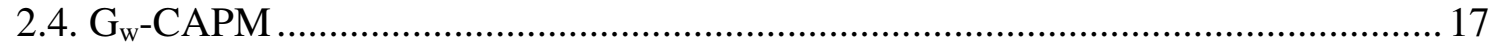

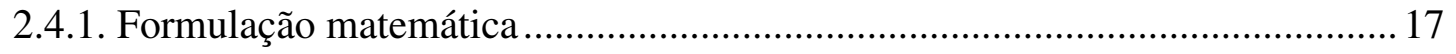

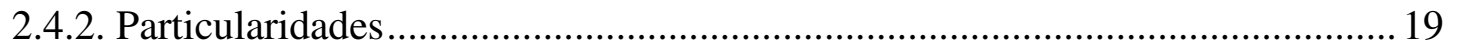

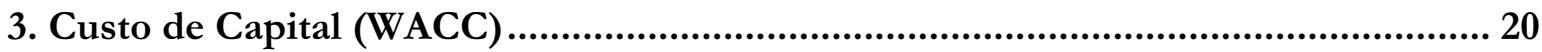

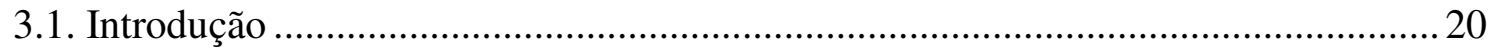

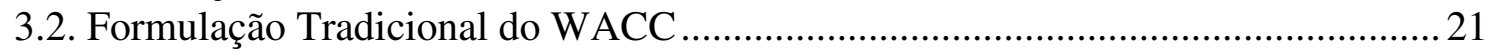

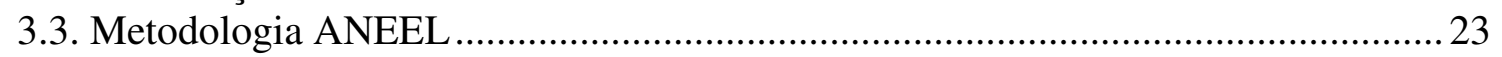

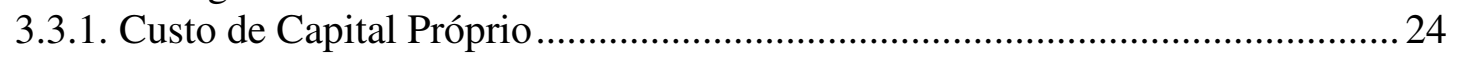

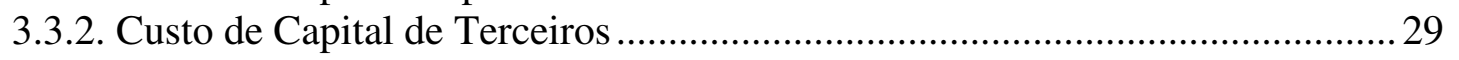

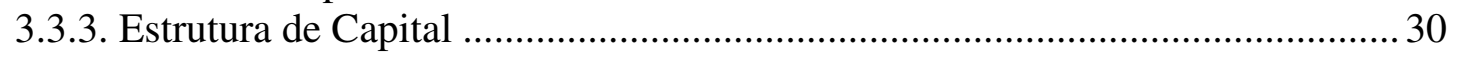

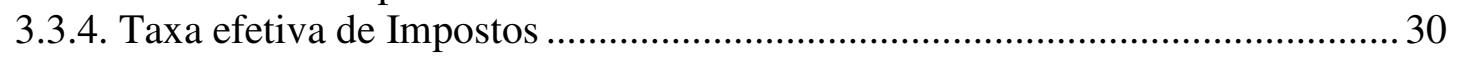

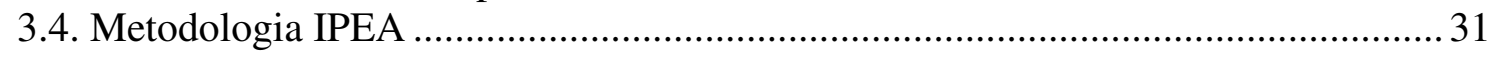

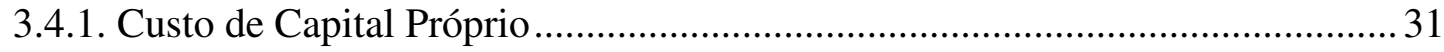

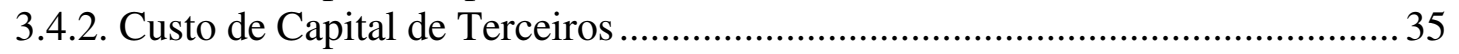

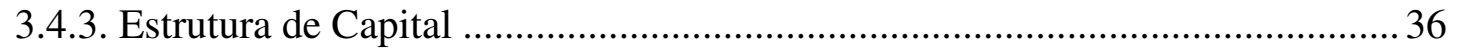

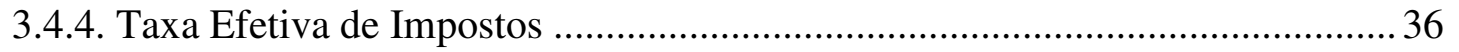

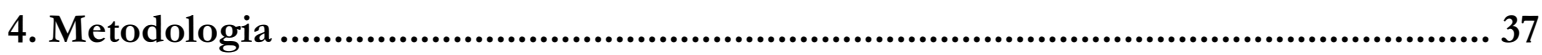

4.1. Metodologia para o CAPM e modelos variantes ....................................................... 37

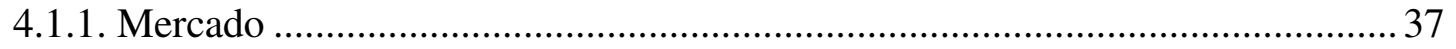

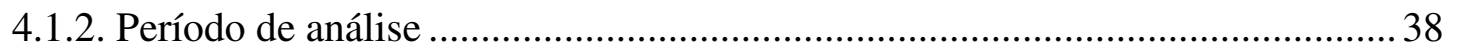

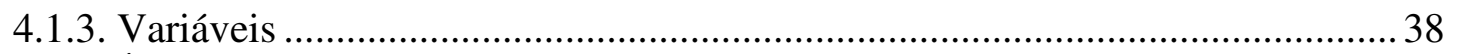

4.1.4. Índices para o mercado local de telefonia fixa.................................................. 41

4.1.5. Avaliação de desempenho dos modelos variantes do CAPM............................ 42 


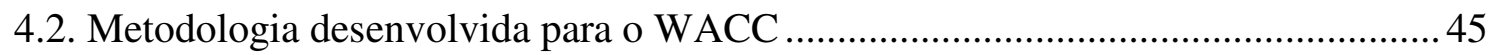

4.2.1. Custo de Capital Próprio ...................................................................................... 46

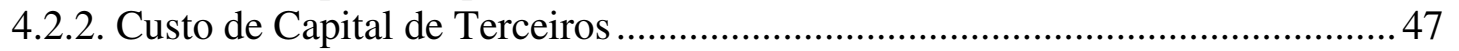

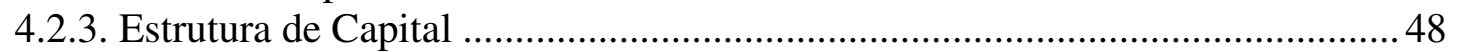

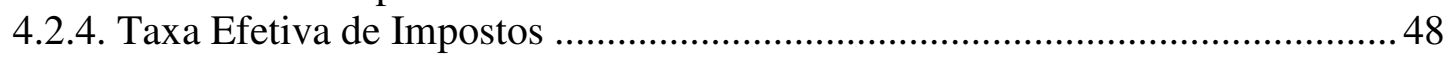

4.2.5. Avaliação de desempenho da metodologia................................................... 48

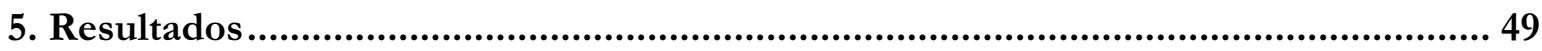

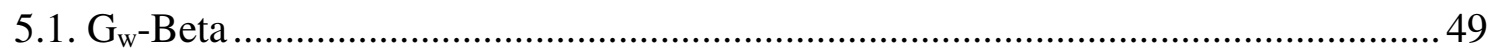

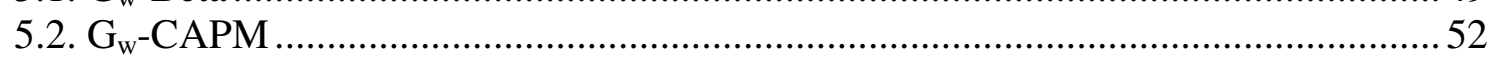

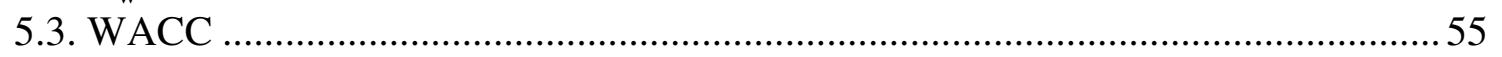

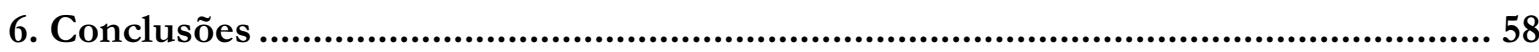

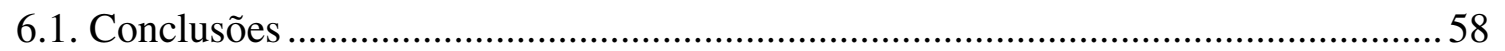

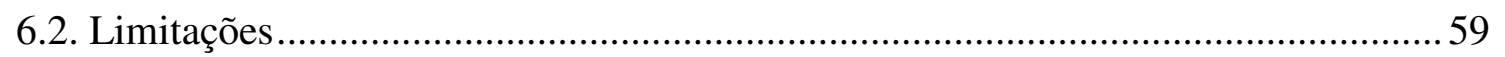

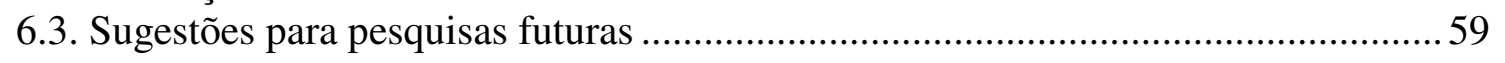

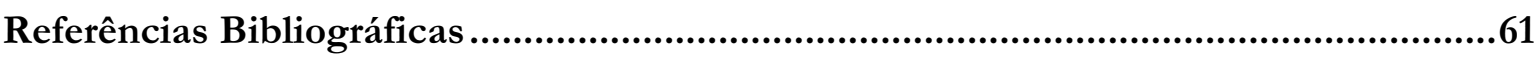

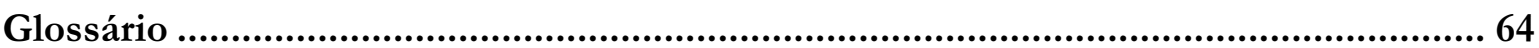

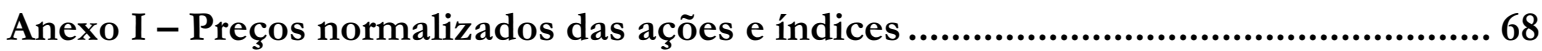

Anexo II - Modelos europeus utilizados para o cálculo do custo de capital próprio ... 69

Anexo III - Diversas figuras para os índices ponderados ITBR-P e ITEU-P ............. 70

Anexo IV - Valores médios de $\mathbf{G}_{\mathrm{w}}$-Beta para cada uma das ações .............................. 72

Anexo V - REQM e Jensen para os índices ponderados ITBR-P e ITEU-P................ 73

Anexo VI - Custo de Capital das diversas metodologias............................................ 74

Anexo VII - Outros parâmetros utilizados no cálculo do WACC............................... 75

Anexo VIII - Taxa de Desconto da Inflação .............................................................. 76

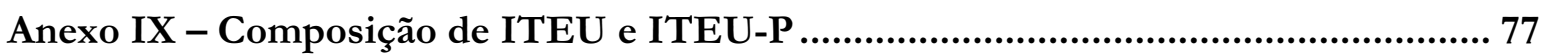




\section{RESUMO}

Neste ano a Anatel começou a adotar um novo modelo para as tarifas de interconexão das diversas áreas de telecomunicações do Brasil. Nesse modelo o WACC e o CAPM têm um papel central no cálculo da remuneração do capital empregado em cada setor. No caso do CAPM, entretanto, há muitas controvérsias sobre a sua aplicabilidade a países emergentes. ESTRADA (2002, 2003), por exemplo, encontrou resultados mais plausíves para esses países utilizando o modelo D-CAPM, uma variação do CAPM baseada no risco Downside. Sabe-se, por outro lado, que o CAPM é uma composição média entre os riscos Downside e Upside. Neste sentido, o objetivo deste trabalho é propor uma generalização do CAPM $\left(\mathrm{G}_{\mathrm{w}}-\mathrm{CAPM}\right)$, baseada em uma ponderação dos riscos Downside e Upside, e analisar a existência de modelos intermediários que estimem melhor o retorno do mercado local de telefonia fixa do Brasil, com vistas à nova orientação a custos adotada. Outro objetivo é elaborar uma metodologia específica para a telefonia fixa e aplicar o $\mathrm{G}_{\mathrm{w}}-\mathrm{CAPM}$ no cálculo do custo de capital próprio, analisando se há ou não diferenças significativas no resultado final do custo de capital do setor. $\mathrm{Na}$ avaliação do poder de estimação dos modelos utilizou-se o índice de Jensen e o REQM. Mostra-se, assim, que realmente há uma determinada combinação entre os riscos Downside e Upside que estima melhor o retorno das operadoras do setor e do mercado de telefonia fixa como um todo. Além disso, conclui-se que há diferenças significativas no cálculo do custo de capital quando o modelo utilizado é o $\mathrm{G}_{\mathrm{w}}$-CAPM.

Palavras-chave: CAPM, $\mathrm{G}_{\mathrm{w}}$-CAPM, Custo de Capital, WACC, Telecomunicações 


\section{Abstract}

This year Anatel began to adopt a new model to the interconnection tariffs to the several telecommunication areas of Brazil. According to this model, the WACC and the CAPM have a central role on determining the remuneration of the investment on each sector. However, there are much controversy about the applicability of CAPM to the emergent countries. For example, Estrada $(2002,2003)$ found more reasonable results to these countries using the D-CAPM, a variation of CAPM based on the Downside risk. It is also known that the CAPM is an average composition between the Donwside and Upside risks. The purpose of this work is to propose a generalization of the CAPM $\left(\mathrm{G}_{\mathrm{w}}-\mathrm{CAPM}\right)$, based on the weight of the Downside and Upside risks and analyse the existence of intermediate models that can evaluate more precisely the return of the brazilian local market of fixed telephony, aiming the new cost orientation adopted. Other objective is to build a specific methodology to the fixed telephony and apply the $G_{w}-C A P M$ on the determination of the own capital cost, verifying whether there are significant differences on the final result of the sector capital cost. In the evaluation of the valuation power of the models, the Jensen index and the REQM were used. It is shown, therefore, that there is really a certain combination between the Downside and the Upside risks that evaluates more accurately the return of the sector operating companies and the fixed telephony market as a whole. In addition to this, we conclude that there are significant differences on determining the cost of capital when the model used is the $\mathrm{G}_{\mathrm{w}}$-CAPM.

Key-words: CAPM, $\mathrm{G}_{\mathrm{w}}-\mathrm{CAPM}$, Cost of Capital, WACC, Telecommunications. 


\section{LISTA DE ILUSTRAÇÕES}

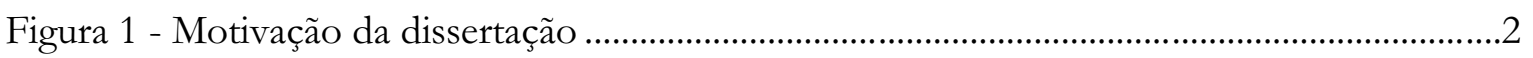

Figura 2 - Estrutura geral da dissertação.............................................................................................

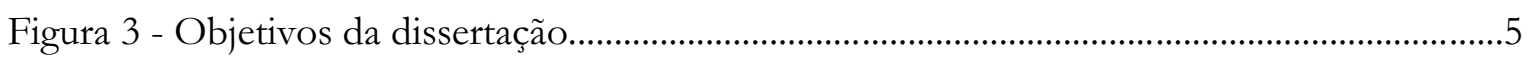

Figura 4 - CML - Capital Market Line (Fonte: COSTA e ASSUNÇÃO, 2005) ......................... 11

Figura 5 - SML: Security Market Line (Fonte: COSTA e ASSUNÇÃO, 2005) ........................... 12

Figura 6 - Valores de $G_{\mathrm{w}}$-Beta para os índices ITBR e ITEU …………………….................... 50

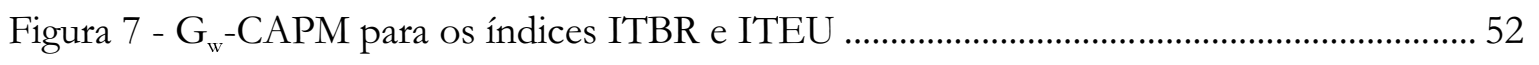

Figura 8 - Valores de Jensen para os índices ITBR e ITEU …………………………………....... 54

Figura 9 - Preços de cada uma das ações que compõem os índices ITBR e ITEU ................... 68

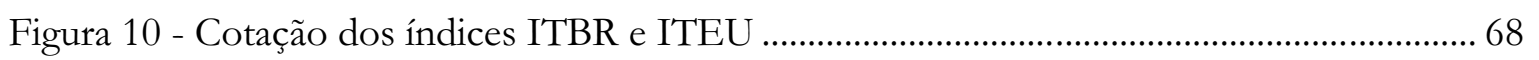

Figura $11-\mathrm{G}_{\mathrm{w}}$-Beta para os índices ponderados ITBR-P e ITEU-P ........................................... 70

Figura 12 - Valores de $G_{\mathrm{w}}-\mathrm{CAPM}$ para os índices ponderados ITBR-P e ITEU-P.................... 70

Figura 13 - Valores de Jensen para os índices ponderados ITBR-P e ITEU-P ........................... 71 


\section{LISTA DE TABELAS}

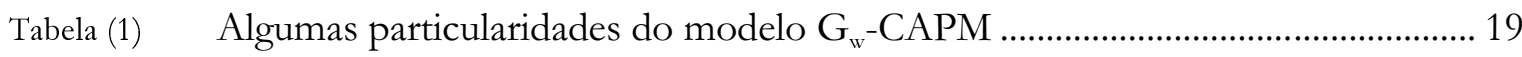

Tabela (2) Estimativa do Custo de Capital Próprio obtido por ANEEL (2006) para o setor de energia elétrica do Brasil.

Tabela (3) Estimativa do Custo de Capital de Terceiros obtido por ANEEL (2006) para o setor de energia elétrica do Brasil

Tabela (4) Estimativa do Custo de Capital Próprio obtido por BRAGANÇA et al (2006) para o setor de telecomunicações do Brasil.

Tabela (5) Estimativa do Custo de Capital de Terceiros obtido por BRAGANÇA et al (2006) para o setor de telecomunicações do Brasil 35

Tabela (6) Detalhes da variável Retorno empregada na metodologia desenvolvida 39

Tabela (7) Características das principais variáveis utilizadas na Metodologia desenvolvida 40

Tabela (8) Retorno do S\&P 500, retorno do USTB10 e prêmio de risco utilizados na Metodologia desenvolvida 41

Tabela (9) Características das ações e índices utilizados ................................................................... 42

Tabela (10) Valores de $G_{w}$-Beta para as empresas dos EUA utilizadas como proxy................. 46

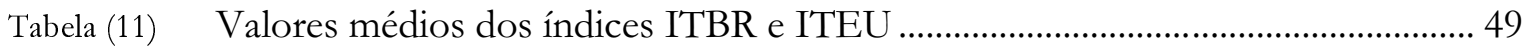

Tabela (12) Valores médios dos índices ponderados ITBR-P e ITEU-P ................................. 51

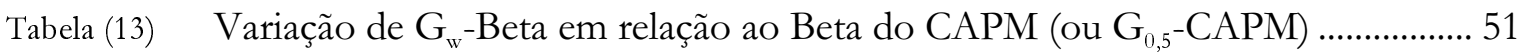

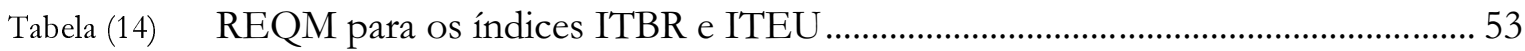

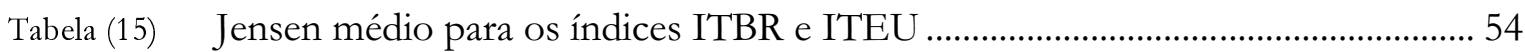

Tabela (16) Principais parâmetros utilizados no cálculo do WACC (valores em \%) ............... 55

Tabela (17) Variação do custo de capital com base no $G_{w}-C A P M$ em relação ao CAPM..... 55

Tabela (18) WACC (em \%) obtido por trabalhos acadêmicos e profissionais ........................... 56

Tabela (19) Valores médios de $G_{\mathrm{w}}$-Beta para ações TSP, BRP e TNE ...................................... 72

Tabela (20) Valores médios de $G_{w}$-Beta para ações VZ, ATT e BLS......................................... 72

Tabela (21) REQM para os índices ponderados ITBR-P e ITEU-P ........................................... 73

Tabela (22) Jensen para os índices ponderados ITBR-P e ITEU-P ............................................ 73

Tabela (23) Características das ações e índices utilizados no ITEU e ITEU-P.......................... 77 


\section{INTRODUÇÃO}

No ano de 2003, com base no Decreto 4.733/2003, o Governo Federal orientou que as tarifas de interconexão ${ }^{1}$ do setor de telecomunicações fossem determinadas com base nos custos incorridos e no capital empregado na prestação dos serviços.

Considerando essa decisão, a Anatel, que tem entre suas funções a implementação de políticas públicas de telecomunicações, determinou por meio da Resolução nº 396, de 30 de março de 2005, que todas as operadoras com Poder de Mercado Significativo (PMS) ${ }^{2}$ deverão apurar os custos incorridos e o capital empregado em cada um dos seus negócios e serviços/produtos oferecidos.

A determinação dos custos será feita com base no modelo LRIC (Long-Run Incremental Cost), que apura os custos e o capital incorrido na prestação de um determinado negócio e serviço/produto e aplica uma taxa de remuneração adequada sobre o capital empregado, da seguinte forma:

EQ. (1) $\quad \mathrm{CC}_{\mathrm{i}}=\mathrm{CE}_{\mathrm{i}} \times \mathrm{WACC}_{\mathrm{i}}$

\footnotetext{
${ }^{1}$ Interconexão: Ligação entre redes de telecomunicações funcionalmente compatíveis, de modo que os usuários de serviços de uma das redes possam comunicar-se com usuários de serviço de outra ou acessar serviços nelas disponíveis. A interconexão é cobrada de uma operadora para outra.

${ }^{2}$ Poder de Mercado Significativo: posição que possibilita influenciar de forma significativa as condições do mercado relevante, assim considerada pela Anatel. É muito provável que todas as três Concessionárias do mercado local de telefonia fixa sejam consideradas como possuidoras de PMS.
} 
sendo

CC: Custo de Capital empregado em um serviço/produto i;

$\mathrm{CE}_{\mathrm{i}}$ : Custo Empregado líquido médio incorrido no serviço/produto i; e

WACC: custo médio ponderado de capital.

Como se observa na equação anterior, regulamentada em ANATEL (2005), a taxa de retorno será calculada com base no Custo Médio Ponderado de Capital (Weigthed Average Cost of Capital - WACC), que tem no custo de capital próprio um dos parâmetros mais importantes. O custo de capital próprio, por sua vez, é calculado pela maior parte dos órgãos reguladores de telecomunicações através do CAPM, como mostra BRAGANÇA et al.(2006).

De forma esquemática e resumida, a motivação apresentada anteriormente é resumida na Figura 1 .

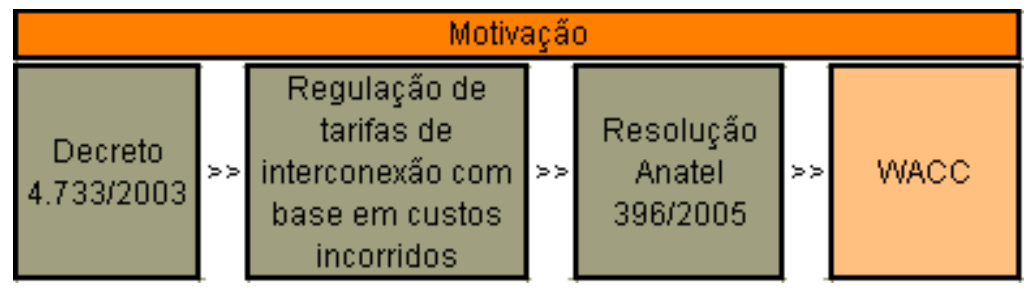

Figura 1 - Motivação da dissertação

Por outro lado, embora o CAPM seja o modelo mais utilizado atualmente, sempre houve muitas controvérsias sobre a sua eficácia. Tanto é assim que diversas alternativas foram sendo propostas desde sua criação na década de 60 até hoje, como por exemplo, o APT (Arbitrage Pricing Theory), desenvolvido por ROSS (1976), e o DGM (Dividend Growth Model), proposto por GORDON (1962).

Outra crítica que se faz ao CAPM é com relação à sua aplicabilidade a países emergentes. ESTRADA (2002, 2003), por exemplo, defende empiricamente que, para esses países, o cálculo do CAPM deve considerar apenas o risco Downside, que seria implementado através do modelo D-CAPM (Downside CAPM). 
Mas por que desconsiderar o risco Upside? Será que não há uma combinação dos riscos Downside e Upside que apresente resultados melhores do que o CAPM e o D-CAPM?

Um dos objetivos deste trabalho é justamente responder a essa pergunta para o caso das telecomunicações no Brasil, em específico, para o mercado de telefonia fixa. Para tal será elaborada uma generalização do CAPM, denominada de $G_{w}-C A P M$ e descrita em função do peso w, que pode abranger todas as combinações de risco Downside e Upside. Para determinados valores do peso w, $\mathrm{G}_{\mathrm{w}}$-CAPM descreve o modelo CAPM ou D-CAPM.

A avaliação do melhor peso para a telefonia fixa do Brasil será feita com base no modelo que melhor estimar o retorno desse setor, sendo que o erro de estimativa será calculado pelo Índice de Jensen e pelo REQM (Raiz do Erro Quadrático Médio). Na representação do setor foi elaborado um índice da telefonia fixa do Brasil, composto por ações das principais concessionárias de telefonia do Brasil, e chamado de ITBR (Índice de Telecomunicações do Brasil). Adicionalmente, com o intuito de comparação com o Brasil, foi elaborado um índice com as principais concessionárias de telefonia dos EUA, chamado de ITEU (Índice de Telecomunicações dos EUA) ${ }^{3}$.

Outro objetivo desta dissertação é avaliar se a utilização do $\mathrm{G}_{\mathrm{w}}-\mathrm{CAPM}$ dentro do cálculo do Custo Médio Ponderado de Capital (WACC) é significativa ou não. Para esta análise foi desenvolvida uma metodologia para calcular o WACC, com base em ANEEL (2006) e BRAGANÇA et al. (2006).

Resumindo, esta dissertação procura analisar e comparar os modelos CAPM, D-CAPM

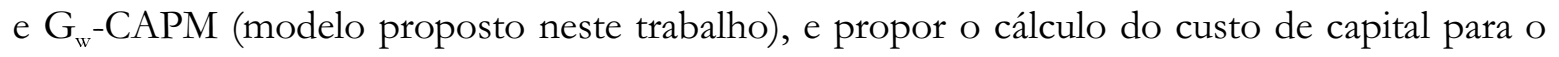
setor de telefonia fixa com base no WACC e nos três modelos anteriores, conforme mostra a estrutura geral da dissertação, apresentada na Figura 2 .

\footnotetext{
${ }^{3}$ Vale mencionar que os dois índices serão utilizados exclusivamente na comparação entre os modelos CAPM, DCAPM e $\mathrm{G}_{\mathrm{w}}$ CAPM. Na análise das metodologias desenvolvidas para o WACC serão utilizados para análise outros parâmetros.
} 


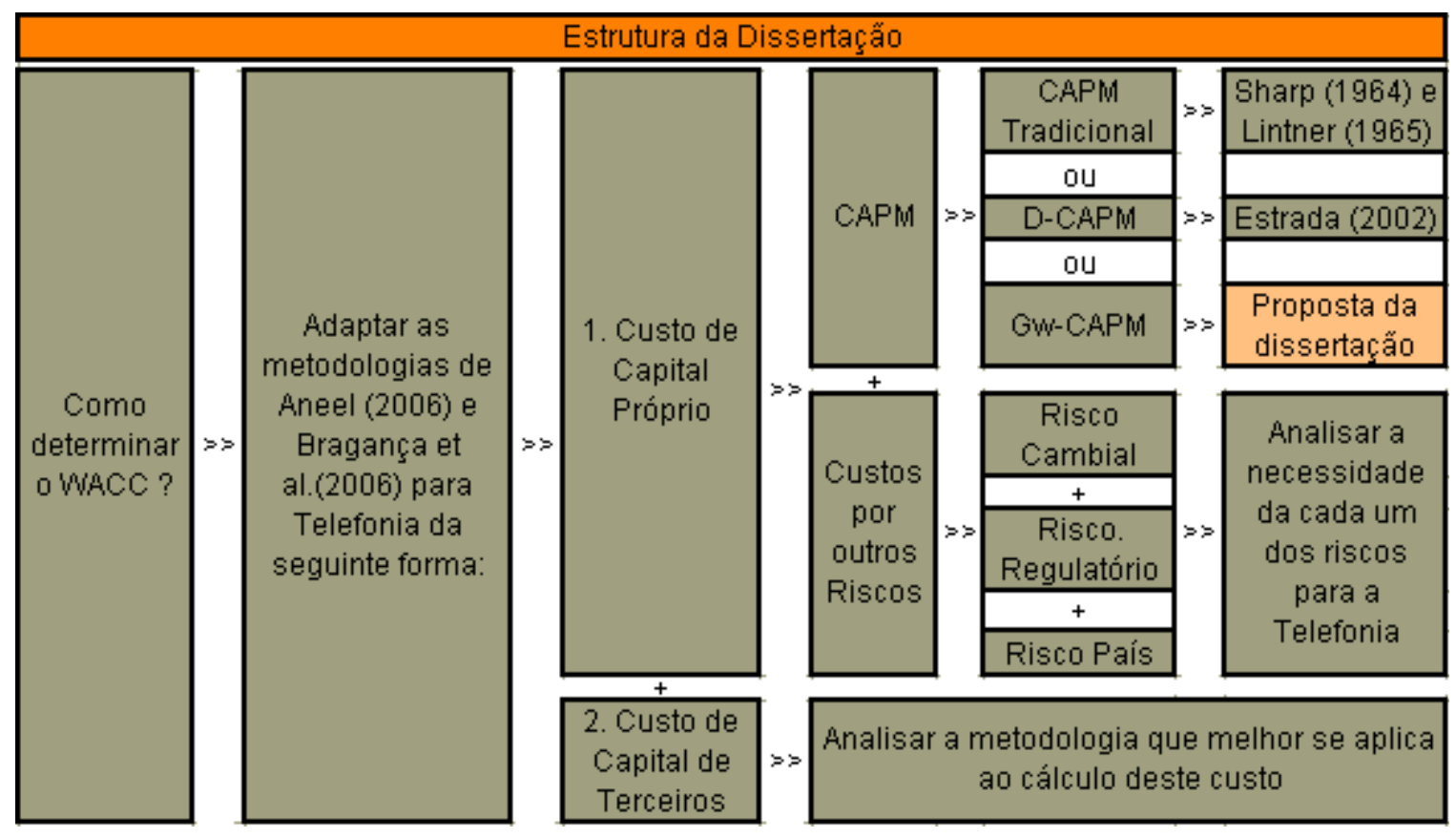

Figura 2 - Estrutura geral da dissertação

De forma esquemática, como principais objetivos desta dissertação destacam-se os seguintes tópicos:

(a) Propor uma generalização para o CAPM, chamada de $\mathrm{G}_{\mathrm{w}}-\mathrm{CAPM}$, comparando os resultados para os índices ITBR e ITEU em termos de poder de previsão, com base no índice de Jensen e no REQM;

(b) Propor uma metodologia para o cálculo do custo de capital para o setor de telefonia fixa do Brasil através da composição entre o WACC e as outras variações do CAPM - DCAPM e $\mathrm{G}_{\mathrm{w}}-\mathrm{CAPM}$, comparando as diferenças entre elas.

Na Figura 3 é apresentado um resumo esquemático com os objetivos. 


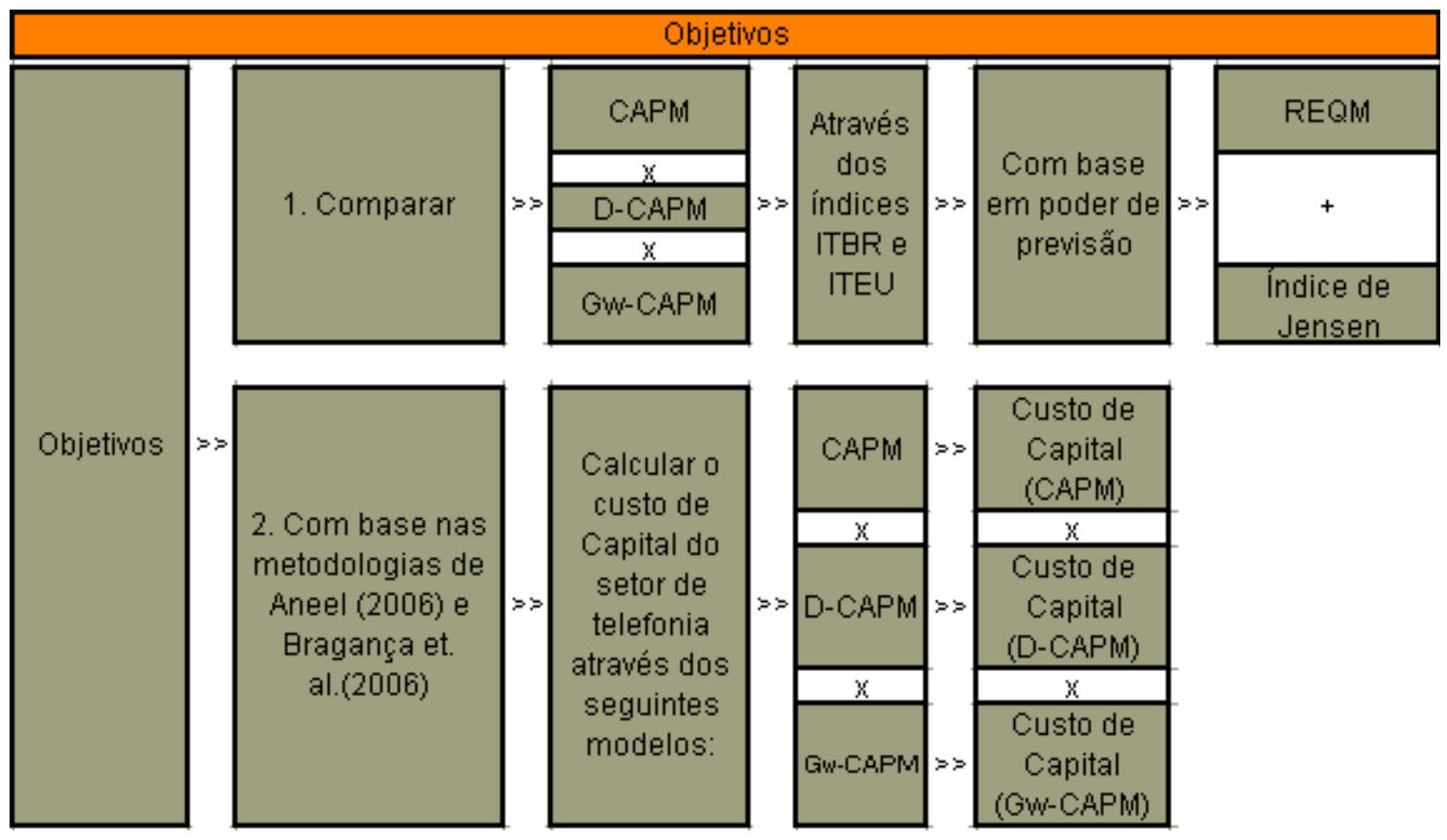

Figura 3 - Objetivos da dissertação

Para a comparação entre os custos de capital obtidos através do WACC/CAPM, WACC/D-CAPM e WACC/ $G_{w}-C A P M$ serão utilizados os betas médios das ações que compõem o ITEU, conforme a metodologia apresentada no Capítulo 3.

Como índice de mercado, para ambos os índices e em todas as ocasiões necessárias, utilizou-se o S\&P500 - índice mais importante dos EUA, composto pelas 500 maiores empresas do mercado local. E como ativo livre de risco o USTB10 - título do Tesouro americano com vencimento de 10 anos e duration de aproximadamente 8 anos.

Finalmente, no segundo capítulo será desenvolvida uma descrição sobre o modelo tradicional CAPM e algumas de suas variações, D-CAPM e $G_{w}-C A P M$. As principais características da metodologia WACC/CAPM serão tratadas no terceiro capítulo. De maneira especial será apresentada uma metodologia para cálculo de custo de capital em setores regulados, elaborada com base em metodologia da ANEEL - ANEEL (2006) - e do IPEA, desenvolvida por BRAGANÇA et al. (2006), e apresentada no Capítulo quarto. No quinto serão abordados os resultados empíricos obtidos. E no sexto capítulo serão tecidas considerações sobre as conclusões, limitações do trabalho e sugestões de trabalhos futuros. 


\section{CAPM E MODElos DeRIVAdos}

Enquanto a abordagem clássica de média-variância, desenvolvida por MARKOWITZ (1959), fornece uma maneira ótima para a distribuição dos recursos em um investimento, o modelo CAPM foca a questão do apreçamento de ações sob a ótica de um mercado em equilíbrio e dentro de um contexto de média-variância. Embora o CAPM tenha seja o modelo mais utilizado, desde sua elaboração, na década de 60, até hoje, surgiram algumas controvérsias com relação à aplicabilidade do fator Beta como medida de risco. ESTRADA (2002), por exemplo, altera o CAPM tradicional, utilizando uma abordagem do tipo média-semivariância no cálculo do Beta, chamando o modelo de D-CAPM. Seguindo a linha de raciocínio do autor, que utiliza semivariância negativa, este capítulo apresenta uma generalização da semivariancia, considerando em um único modelo uma ponderação entre a semivariância positiva e a negativa para o cálculo do Beta. A esse modelo foi dado o nome de $\mathrm{G}_{\mathrm{w}}-\mathrm{CAPM}$.

Neste Capítulo são apresentados os modelos CAPM, D-CAPM e $G_{w}-C A P M$, bem

como suas respectivas formulações matemáticas. Estas formulações serão feitas para uma carteira genérica, o que não invalida a sua aplicação para uma ação individual qualquer.

\subsection{CAPM}

O CAPM - Capital Asset Pricing Model, desenvolvido por John Lintner (LINTNER, 1965) e Willian Sharpe (SHARPE, 1964), é um modelo para o apreçamento de ativos pelo 
mercado em equilíbrio e dentro de um contexto de otimização por média-variância (COSTA E ASSUNÇÃO, 2005).

E o que significa uma otimização por média-variância? De acordo com MARKOWITZ (1959), isso é o mesmo que supor duas hipóteses: (1) diante de riscos iguais, o investidor sempre escolhe o investimento com maior retorno; e (2) diante de retornos iguais, o investidor escolhe sempre o investimento de menor risco.

Com o CAPM é possível verificar que o risco de um ativo qualquer, medido pela variância, pode ser decomposto em dois termos: um inerente ao mercado (risco sistêmico) e outro que pode ser eliminado pela diversificação dos ativos (risco não-sistêmico). A principal hipótese do modelo é a de que todos os investidores utilizam a otimização por média-variância para a alocação de seus recursos, isto é, consideram que o melhor ativo é aquele que apresenta o maior retorno médio com a menor variância, ou a menor variância possível com o maior retorno.

As aplicações principais do CAPM são a estimação de retornos de ativos e o cálculo do custo de capital próprio de uma empresa, negócio ou produto.

No caso do custo de capital próprio, DAMODARAN (2002), por exemplo, afirma que a mensuração do custo de capital próprio pode se dar utilizando modelos de risco e retorno. Entre esses modelos, tem-se o Capital Asset Pricing Model - CAPM, pelo qual o risco é mensurado em relação a um único fator de mercado; o Arbitrage Pricing Theory - APT, em que o custo do capital próprio é estimado pela sensibilidade deste face aos múltiplos fatores econômicos não-específicos e o modelo de fatores múltiplos, que é dado pela sua sensibilidade em relação a variáveis macroeconômicas, e outros modelos alternativos de fator único e fatores múltiplos. Mas o mais utilizado é o CAPM.

DAMODARAN (2002) define também que o custo de capital próprio é "a taxa de retorno que os investidores exigem para fazer um investimento em capital de risco em uma empresa”.

Finalmente, enquanto a abordagem clássica de média-variância, desenvolvida por MARKOWITZ (1959), fornece uma maneira ótima para a distribuição dos recursos em um investimento, o CAPM foca a questão do apreçamento de ativos sob a ótica de um mercado em equilíbrio. No próximo item este conceito será demonstrado matematicamente. 


\subsubsection{Formulação matemática}

Para um melhor entendimento do CAPM é importante tecer algumas considerações iniciais sobre a nomenclatura que será utilizada ao longo do trabalho. Seja i uma ação qualquer negociada em bolsa. O retorno de i será dado por $\mathrm{R}_{\mathrm{i}}$, uma variável aleatória em função de i. $\mathrm{O}$ retorno esperado da variável aleatória anterior será denotado por $r_{i}$, sendo $r_{i}=E\left(R_{i}\right)$. Da mesma forma, seja uma carteira qualquer P, com retorno descrito descrita pela EQ. (2).

EQ. (2)

$$
\mathrm{R}_{\mathrm{P}}=\mathrm{a}_{1} \mathrm{R}_{1}+\mathrm{a}_{2} \mathrm{R}_{2}+\ldots+\mathrm{a}_{\mathrm{i}} \mathrm{R}_{\mathrm{i}}
$$

$\mathrm{Na}$ equação anterior, $\mathrm{R}_{\mathrm{p}}$ é uma variável aleatória e os pesos $\mathrm{a}_{\mathrm{i}}$ satisfazem a condição de que $\left(a_{1}+a_{2}+\ldots+a_{i}\right)=1$.

$O$ valor esperado para $R_{p}$ será representado por $\mu_{\mathrm{p}}$, onde $\mu_{\mathrm{p}}=\mathrm{E}\left(\mathrm{R}_{\mathrm{p}}\right)$. Para o caso de um índice de mercado qualquer vale a mesma formulação: seja, por exemplo, um índice de mercado $M$, com retorno representado por $\mathrm{R}_{\mathrm{M}}$ e também uma variável aleatória; o retorno esperado do índice será dado por $\mu_{M}=E\left(R_{M}\right)$.

Sabendo da nomenclatura anterior, pode-se então escrever o modelo CAPM aplicado a à carteira $\mathrm{P}$, considerando um mercado de referência $\mathrm{M}$, conforme a $\mathrm{EQ}$. (3):

EQ. (3)

$$
r_{P}=r_{f}+\beta_{R_{P}}\left(\mu_{M}-r_{f}\right)
$$

onde

$\mathrm{r}_{\mathrm{P}}$ : retorno esperado pelo modelo CAPM para a carteira $\mathrm{P}$.

$\mathrm{r}_{\mathrm{f}}$ : taxa livre de risco.

$\left(\mu_{\mathrm{M}}-\mathrm{r}_{\mathrm{f}}\right)$ : prêmio de risco do mercado, onde $\mu_{\mathrm{M}}$ é o retorno esperado para o índice de mercado M.

$\beta_{R_{P}}$ : Beta da carteira P, dado pela EQ. (4).

O parâmetro Beta da EQ. (3) é apresentado na EQ. (4): 
EQ. (4)

$$
\beta_{R_{P}}=\frac{\operatorname{Cov}\left(R_{P}, R_{M}\right)}{\operatorname{Var}\left(R_{M}\right)}
$$

sendo

$\mathrm{R}_{\mathrm{P}}$ : variável aleatória com os retornos de $\mathrm{P}$.

$\mathrm{R}_{\mathrm{M}}$ : variável aleatória com os retornos do índice de mercado $\mathrm{M}$.

\subsubsection{Hipóteses adotadas}

Como todo modelo matemático, o CAPM também está apoiado em diversas hipóteses, conforme menciona GIBSON (2000): (1) é assumido que todos os investidores têm as mesmas informações e mantém expectativas idênticas com relação ao futuro; (2) o mercado é perfeitamente competitivo; (3) não há custos de transações para comprar ou vender ativos. (4) os investidores vivem em um mundo isento de impostos; (5) os investidores podem investir ou tomar emprestado à mesma taxa de juros, sendo que não há volatilidade sobre a mesma; e (6) os investidores têm aversão ao risco.

Em tais condições, todos os investidores criariam e manteriam a mesma carteira de mercado eficiente composta por ativos voláteis (GIBSON, 2000).

Como era de se esperar o modelo apresenta também algumas limitações. No próximo item serão mostrados alguns desses problemas e as soluções que foram propostas para contorná-los.

\subsubsection{Problemas na mensuração do Beta}

Conforme já mencionado na EQ. (4), o cálculo do Beta se reduz à estimação da covariância entre uma ação ou carteira e o índice de mercado, ou a variância dos retornos do índice de mercado adotado. ROSS et al. (1995), entretanto, afirma que há três problemas na estimação do Beta que devem ser contornados:

(1) O Beta pode variar com o passar do tempo;

(2) O tamanho da amostra pode ser inadequado; e 
(3) Os Betas são influenciados por variações de endividamento e risco operacional.

Diante do exposto acima, foram apresentadas algumas soluções para esses problemas: a questão da variação do Beta com o tempo foi resolvida calculando-o mensalmente por um período de pouco mais de dois anos (out/03 a out/05).

Ainda assim para evitar quaisquer problemas de variações, sempre que necessário utilizar um único valor de Beta, caso do cálculo do Custo de Capital total, empregou-se um valor médio ao longo do período anterior.

Com relação ao tamanho da amostra, utilizou-se como solução em todos os casos período de 5 anos.

Finalmente, de acordo com ROSS et al.(1995), as variações de endividamento serão contornadas examinando estimativas de betas médios de várias empresas comparáveis do mesmo setor. Neste sentido, a solução adotada no cálculo do custo de capital é o cálculo do beta alavancado e a transformação em desalavancado, com base na estrutura de capital de cada empresa. Através dos Betas desalavancados serão estimados valores médios de Beta para o setor de telefonia fixa do Brasil, conforme será apresentado nos Capítulos 3 e 4.

\subsubsection{CML}

O CML (Capital Market Line) é uma linha de risco/retorno que liga o retorno livre de risco até o ponto tangente à carteira de mercado, conforme pode ser observado na Figura 4 , e descrito na EQ. (5).

EQ. (5)

$$
\mu=r_{f}+\frac{\left(\mu_{M}-r_{f}\right)}{\sigma_{M}} \sigma
$$

sendo

$\mathrm{r}_{\mathrm{f}}:$ retorno do ativo livre de risco

$\mu_{\mathrm{M}^{-}} \mathrm{r}_{\mathrm{f}}:$ Prêmio de risco do mercado

$\sigma_{\mathrm{M}}$ : Desvio-padrão do índice de mercado

$\sigma:$ Desvio-padrão da carteira analisada 
Esta equação define a fronteira eficiente para investimentos com um ativo livre de risco

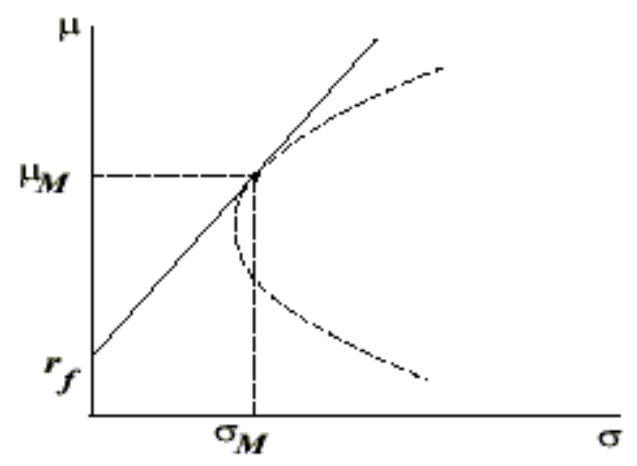

Figura 4 - CML - Capital Market Line (Fonte: COSTA e ASSUNÇÃO, 2005)

Nas palavras de GIBSON (2000), a curvatura da CML pode ser entendida como a recompensa que se espera receber por cada unidade de risco (desvio-padrão) que se corre. Seja ressaltado que uma carteira eficiente deve estar sobre a linha que liga o ativo livre risco até o ponto tangente à carteira de mercado.

O CAPM é obtido diretamente da condição de que a carteira de mercado é um ponto sobre a fronteira da região viável que é tangente à linha CML. Em outras palavras, o CAPM expressa matematicamente a condição de tangência anterior (LUENBERGER, 1998).

\subsubsection{SML}

O SML (Security Market Line) é a linha de mercado descrita pela EQ. (6), que relaciona o risco $(\beta)$ e retorno $(\mu)$, considerando que o risco é calculado pelo Beta e que o seu valor para a carteira de mercado é igual a 1. A Figura 5 mostra em detalhes a linha do SML.

$$
\text { EQ. (6) } \quad \mu=r_{f}+\left(\mu_{M}-r_{f}\right) \beta
$$

onde

$\mu_{\mathrm{M}}$ : retorno esperado para $\mathrm{M}$.

$\mathrm{r}_{\mathrm{f}}$ : taxa do ativo livre de risco.

$\mu$ : variável retorno (eixo y)

$\beta$ : variável risco (eixo $\mathrm{x})$ 


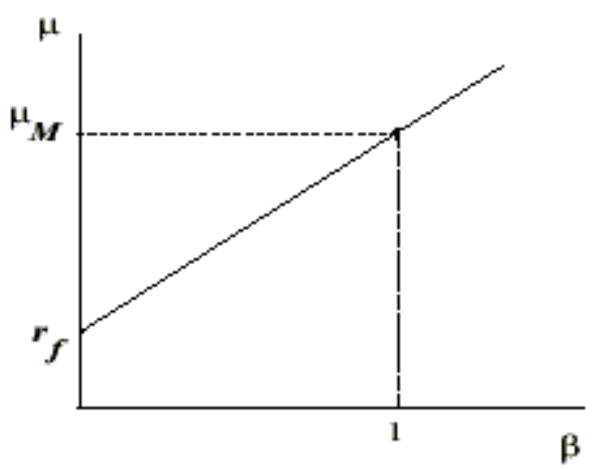

Figura 5 - SML: Security Market Line (Fonte: COSTA e ASSUNÇÃO, 2005)

No próximo item é tratado em detalhes o modelo D-CAPM.

\subsection{D-CAPM}

Embora o CAPM seja o modelo mais utilizado atualmente, há algumas críticas com relação ao seu uso. Uma das mais importante refere-se à medida de risco utilizada, que é a variância. O problema alegado é que ela assegura igual importância para os retornos que estão acima e abaixo do valor médio. HARKER e ZENIOS (2000), por exemplo, afirmam que apenas os eventos que estão abaixo da média são importantes para a medida de risco em investimento. Divergências como essa levaram alguns pesquisadores e analistas de mercado a sugerir uma outra medida de risco: a semivariância, ou variância média dos eventos que ocorrem abaixo da média, como uma medida mais realista do risco (HARKER e ZENIOS, 2000).

Neste contexto, ESTRADA (2002) propõe o modelo D-CAPM. Ele utiliza a semivariância negativa como medida de risco. De acordo com o autor, essa medida é mais plausível para países emergentes.

A diferença entre o CAPM e o D-CAPM refere-se basicamente à forma como o Beta é calculado. O D-CAPM não leva em conta uma estrutura de média-variância, mas sim de média-semivariância negativa. De acordo com BARBOSA e MOTTA (2004), o D-CAPM 
possui como principal característica o fato de utilizar como medida de risco o Downside Beta (D-Beta), que busca avaliar somente o risco de perda sistemático.

No próximo item será dada uma explicação matemática do modelo.

\subsubsection{Formulação matemática}

Seja novamente uma determinada carteira $\mathrm{P}$, com retornos $\mathrm{R}_{\mathrm{P}}$, e uma carteira de mercado $\mathrm{M}$, com retornos $\mathrm{R}_{\mathrm{M}}$. Na formulação do D-CAPM, a variância é trocada pela semivariância negativa (svar-) que, para o caso da carteira M, será dada pela EQ. (7).

EQ. (7)

$$
s \operatorname{var}^{-}\left(R_{M}\right)=E\left\{\operatorname{Min}\left[\left(R_{M}-\mu_{M}\right), 0\right]^{2}\right\}
$$

sendo

$\mathrm{R}_{\mathrm{M}}$ : variável aleatória com os retornos de $\mathrm{M}$.

$\mu_{\mathrm{M}}$ : retorno esperado para $\mathrm{M}$, calculado pela média aritmética dos retornos passados.

$\mathrm{E}\{\}$ : valor esperado.

Na EQ. (7) fica claro que só entra na contagem da semivariância negativa (svar) os retornos de mercado que estiverem abaixo do valor esperado. Os demais são desconsiderados.

Com relação à semicovariância negativa $\left(\mathrm{scov}^{-}\right)$entre a carteira $\mathrm{P}$ e o mercado $\mathrm{M}$, o calculo é dado pela EQ. (8).

$$
\text { EQ. (8) } \quad s \operatorname{cov}^{-}\left(R_{P}, R_{M}\right)=E\left\{\operatorname{Min}\left[\left(R_{P}-\mu_{P}\right), 0\right] \operatorname{Min}\left[\left(R_{M}-\mu_{M}\right), 0\right]\right\}
$$

onde

$R_{\mathrm{P}}$ : variável aleatória com os retornos de $\mathrm{P}$.

$\mu_{P}$ : retorno esperado para $\mathrm{P}$, calculado pela média aritmética dos retornos passados.

$\mathrm{R}_{\mathrm{M}}$ : variável aleatória com os retornos de $\mathrm{M}$.

$\mu_{M}$ : retorno esperado para $\mathrm{M}$, calculado pela média aritmética dos retornos passados. 
Novamente, no cômputo de scov` só entram os valores que estão abaixo do retorno esperado, tanto para a carteira $\mathrm{P}$ quanto para a carteira de mercado M. Os restantes são desconsiderados.

Expostas a EQ. (7) e a EQ. (8) pode-se então escrever o valor do risco do D-CAPM, representado por $\beta_{R_{P}}^{d}$ (ou D-Beta), de acordo com a EQ. (9):

EQ. (9)

$$
\beta_{R_{P}}^{d}=\frac{s \operatorname{cov}^{-}\left(R_{P}, R_{M}\right)}{s \operatorname{var}^{-}\left(R_{M}\right)}
$$

onde

$\mathrm{R}_{\mathrm{P}}$ : variável aleatória com os retornos de $\mathrm{P}$.

$\mathrm{R}_{\mathrm{M}}$ : variável aleatória com os retornos de $\mathrm{M}$.

Por analogia com a EQ. (3) e tomando as equações anteriores, pode-se então escrever na EQ. (10) o retorno esperado pelo D-CAPM para uma carteira P:

EQ. (10)

$$
r_{D_{P}}=E\left(r_{P}\right)=r_{f}+\beta_{R_{P}}^{d} \cdot\left(\mu_{M}-r_{f}\right)
$$

sendo $r_{D_{P}}:$ retorno esperado pelo D-CAPM para P;

$\mathrm{r}_{\mathrm{f}}$ taxa do ativo livre de risco;

$\left(\mu_{\mathrm{M}}-\mathrm{r}_{\mathrm{f}}\right)$ : prêmio de risco, sendo $\mu_{\mathrm{M}}$ o retorno esperado para M;

$\beta_{R_{P}}^{d}:$ Beta do D-CAPM para P, calculado pela EQ. (9)

Com a EQ. (10) fica evidente que a única diferença entre o D-CAPM e o CAPM é a forma de calcular o Beta. O ativo livre de risco e o prêmio de risco de mercado se mantêm da mesma forma. Vale lembrar também que as equações deste item se aplicam tanto a uma carteira como a uma ação individual. 


\subsection{U-CAPM}

Ao contrário do D-CAPM, o U-CAPM ${ }^{4}$ tem como principal característica o fato de utilizar um risco positivo, denominado aqui de Upside Beta, representado por $\beta_{R_{P}}^{u}$ (ou UBeta), e medido pela semivariância positiva. Esse modelo procura quantificar o risco devido aos retornos que sejam superiores ao retorno esperado.

Abaixo pode ser observada uma explicação mais aprofundada sobre a formulação matemática

\subsubsection{Formulação matemática}

Considerando a mesma nomenclatura que vem sendo utilizada até o momento, a semivariância positiva é descrita pela EQ. (11)

$$
s \operatorname{var}^{+}\left(R_{M}\right)=E\left\{\operatorname{Max}\left[\left(R_{M}-\mu_{M}\right), 0\right]^{2}\right\}
$$

onde

$\mathrm{R}_{\mathrm{M}}$ : variável aleatória com os retornos de $\mathrm{M}$.

$\mu_{\mathrm{M}}$ : retorno esperado para $\mathrm{M}$, dado pela média dos retornos passados.

$\mathrm{E}\{\}$ : valor esperado.

$\mathrm{Na}$ EQ. (11) fica claro que só entra na contagem da semivariância positiva (svar ${ }^{+}$) os retornos de mercado que estiverem acima do valor esperado. Os demais são desconsiderados.

Com relação à semicovariância positiva $\left(\mathrm{scov}^{+}\right)$entre os retornos de $\mathrm{P}$ e $\mathrm{M}$, o cálculo é dado pela EQ. (12).

${ }^{4} \mathrm{O}$ modelo U-CAPM ainda não foi apresentado na literatura de finanças, mas sua descrição feita aqui é análoga a do D-CAPM. O objetivo deste item não é aprofundar sobre ele mas apenas utilizá-lo na formulação do modelo central deste trabalho: o $\mathrm{G}_{\mathrm{w}} \mathrm{CAPM}$. 
EQ. (12)

$$
s \operatorname{cov}^{+}\left(R_{P}, R_{M}\right)=E\left\{\operatorname{Max}\left[\left(R_{P}-\mu_{P}\right), 0\right] \operatorname{Max}\left[\left(R_{M}-\mu_{M}\right), 0\right]\right\}
$$

sendo

$\mathrm{R}_{\mathrm{P}}$ :variável aleatória com os retornos de $\mathrm{P}$;

$\mu_{P}$ : retorno esperado para $\mathrm{P}$, calculado pela média retornos passados;

$\mathrm{R}_{\mathrm{M}}$ : variável aleatória com os retornos de $\mathrm{M}$.

$\mu_{M}$ : retorno esperado para $\mathrm{M}$, sendo calculado pela média dos retornos passados.

No cômputo de $\operatorname{scov}^{+}$só entram os valores que estão acima do retorno esperado, tanto para a carteira P como para a carteira de mercado M. Os restantes são desconsiderados.

Com base na EQ. (11) e na EQ. (12) escreve-se então o Beta para o U-CAPM $\left(\beta_{R_{P}}^{u}\right)$, conforme a equação a seguir:

EQ. (13)

$$
\beta_{R_{P}}^{u}=\frac{s \operatorname{cov}^{+}\left(R_{P}, R_{M}\right)}{s \operatorname{var}^{+}\left(R_{M}\right)}
$$

sendo

$\mathrm{R}_{\mathrm{P}}$ : variável aleatória com os retornos de $\mathrm{P}$;

$\mathrm{R}_{\mathrm{M}}$ : variável aleatória com os retornos da carteira de mercado.

Associando as equações anteriores pode-se escrever o retorno esperado pelo U-CAPM, conforme a EQ. (14):

EQ. (14)

$$
r_{U_{P}}=E\left(R_{P}\right)=r_{f}+\beta_{R_{P}}^{u}\left(\mu_{M}-r_{f}\right)
$$

onde

$r_{U_{P}}:$ retorno esperado pelo U-CAPM para P;

$\mathrm{r}_{\mathrm{f}}$ : taxa do ativo livre de risco;

$\left(\mu_{\mathrm{M}}-\mathrm{r}_{\mathrm{f}}\right)$ : prêmio de risco, sendo $\mu_{\mathrm{M}}$ o retorno esperado para $\mathrm{M}$;

$\beta_{R_{P}}^{u}$ : Beta do U-CAPM para os retornos $\mathrm{R}_{\mathrm{P}}$, calculado pela EQ. (13). 
Todas as equações anteriores se aplicam também a uma ação única. No próximo item serão integrados os modelos D-CAPM e U-CAPM na generalização do CAPM $\left(\mathrm{G}_{\mathrm{w}}{ }^{-C A P M}\right)$.

\section{4. $\mathrm{G}_{\mathrm{w}}-\mathrm{CAPM}$}

Apresentados os modelos D-CAPM e U-CAPM, é possível então propor a generalização do CAPM, com base tanto na semivariância positiva como na semivariância negativa.

Conforme já comentado, ESTRADA (2002) compara o CAPM e o D-CAPM e encontra resultados mais plausíveis para este último, quando são considerados os países emergentes. Mas será que uma combinação entre os modelos U-CAPM e D-CAPM não traz resultados melhores ainda? O objetivo da generalização é avaliar a eficácia da combinação das duas medidas na estimativa do retorno de ações, especificamente, do setor de telefonia fixa local.

\subsubsection{Formulação matemática}

Com base na mesma nomenclatura dos itens anteriores, e considerando pesos w para os riscos Downside e Upside, pode-se escrever a semivariância dos retornos de mercado de acordo com a EQ. (15):

EQ. (15)

$$
s \operatorname{var}_{w}\left(R_{M}\right)=(w) s \operatorname{var}^{+}\left(R_{M}\right)+(1-w) s \operatorname{var}^{-}\left(R_{M}\right)
$$

onde

$\operatorname{svar}_{\mathrm{w}}\left(\mathrm{R}_{\mathrm{M}}\right)$ : semivariância dos retorno de mercado $\left(\mathrm{R}_{\mathrm{M}}\right)$ em função do peso w;

w: peso que varia entre $[0,1]$;

$\mathrm{R}_{\mathrm{M}}$ : variável aleatória com o retorno da carteira de mercado;

$\operatorname{svar}^{+}\left(\mathrm{R}_{\mathrm{M}}\right)$ : função semivariância positiva aplicada a $\mathrm{R}_{\mathrm{M}}$;

svar- $\left(\mathrm{R}_{\mathrm{M}}\right)$ : função semivariância negativa aplicada a $\mathrm{R}_{\mathrm{M}}$. 
Na EQ. (15) algumas considerações são relevantes: se w=0,5 ela se reduz ao cálculo da variância; se $\mathrm{w}=0$, ela é o caso particular da semivariância negativa; e se $\mathrm{w}=1$, da variância positiva.

De outro lado, calculando a semicovariância (scov) entre os retornos de P e M tem-se a EQ. (16).

EQ. (16)

$$
s \operatorname{cov}_{w}\left(R_{P}, R_{M}\right)=(w) . s \operatorname{cov}^{+}\left(R_{P}, R_{M}\right)+(1-w) \cdot s \operatorname{cov}^{-}\left(R_{P}, R_{M}\right)
$$

sendo

w: peso que varia entre $[0,1]$.

$\mathrm{R}_{\mathrm{P}}$ : variável aleatória com os retornos de $\mathrm{P}$;

$\mathrm{R}_{\mathrm{M}}$ : variável aleatória com os retornos de $\mathrm{M}$;

$\operatorname{scov}^{+}()$: função semicovariância positiva;

$\operatorname{scov}^{-}()$: função semicovariância negativa.

$\mathrm{Na}$ equação anterior, se $\mathrm{w}=0.5$, a semicovariância se reduz ao caso particular da covariância; se $\mathrm{w}=0$, ela é o caso particular da semicovariância negativa; e se $\mathrm{w}=1$, da semicovariância positiva.

Com base na EQ. (15) e na EQ. (16) pode-se escrever então o valor do risco $\left(\mathrm{G}_{\mathrm{w}}-\mathrm{Beta}\right)$ considerado no modelo, conforme a EQ. (17):

$$
\beta_{R_{P}}^{g}(w)=\frac{s \operatorname{cov}_{w}\left(R_{P}, R_{M}\right)}{s \operatorname{var}_{w}\left(R_{M}\right)}
$$

sendo

$\mathrm{R}_{\mathrm{P}}$ : variável aleatória com os retornos da carteira $\mathrm{P}$;

$\mathrm{R}_{\mathrm{M}}$ : variável aleatória com os retornos da carteira de mercado $\mathrm{M}$.

Utilizando as equações anteriores tem-se que o retorno esperado pelo $G_{w}-C A P M$ para a carteira P pode ser escrito pela EQ. (18), 
EQ. (18)

$$
r_{G_{P}}(w)=r_{f}+\beta_{R_{P}}^{g}(w) \cdot\left(\mu_{M}-r_{f}\right)
$$

onde

$r_{G_{P}}(w)$ : retorno esperado através $\mathrm{G}_{\mathrm{w}}{ }^{-} \mathrm{CAPM}$ para $\mathrm{P}$ em função de w.

$\mathrm{r}_{\mathrm{f}}$ : é a taxa do ativo livre de risco.

$\left(\mu_{\mathrm{M}}-\mathrm{r}_{\mathrm{f}}\right)$ : prêmio de risco, sendo $\mu_{\mathrm{M}}$ o retorno esperado para $\mathrm{M}$.

$\beta_{R_{P}}^{g}(w)$ : Beta do $\mathrm{G}_{\mathrm{w}}-\mathrm{CAPM}$ para $\mathrm{P}$, em função de w, calculado pela EQ. (17).

A fórmula anterior descreve, portanto, o modelo CAPM generalizado. Fica claro, mais uma vez, que o ativo livre de risco e o prêmio de risco se mantém inalterados em relação ao CAPM tradicional e ao D-CAPM. A única diferença é o parâmetro Beta que, agora, está descrito em função do peso w.

\subsubsection{Particularidades}

Antes de concluir este item, é importante apresentar algumas particularidades que ocorrem no modelo $\mathrm{G}_{\mathrm{w}}$-CAPM. Quando w=0, a generalização descreve o modelo D-CAPM; se $\mathrm{w}=0.5$, os riscos positivos e negativos têm a mesma importância, descrevendo então o modelo CAPM; e se w=1, o modelo considera apenas o risco positivo, representado o caso particular do U-CAPM. As particularidades anteriores são exibidas na Tabela (1), tomando como exemplo uma carteira qualquer P:

Valores atribuídos a w

\begin{tabular}{cccc}
\hline $\mathrm{w}=0$ & $r_{G_{P}}(0)=r_{D_{P}}$ & ou & $\mathrm{G}_{0}-\mathrm{CAPM}=\mathrm{D}-\mathrm{CAPM}$ \\
$\mathrm{w}=0,5$ & $r_{G_{P}}(0,5)=r_{P}$ & ou & $\mathrm{G}_{0,5} \mathrm{CAPM}=\mathrm{CAPM}$ \\
\hline $\mathrm{w}=1$ & $r_{G_{P}}(1)=r_{U_{P}}$ & ou & $\mathrm{G}_{1,0} \mathrm{CAPM}=\mathrm{U}-\mathrm{CAPM}$ \\
\hline Tabela (1) & Algumas particularidades do modelo $\mathrm{G}_{\mathrm{w}}$-CAPM
\end{tabular}

\section{Particularidades}




\section{Custo de Capital (WACC)}

Qual taxa de retorno deve remunerar um investimento no setor de telefonia? Embora não haja unanimidade, nos setores regulados há uma forte tendência em calcular o retorno com base no custo de capital, mais especificamente, Custo Médio Ponderado de Capital (Weigthed Average Cost of Capital, WACC). Neste sentido este Capítulo tem o intuito de apresentar uma introdução sobre o WACC e algumas formulações sobre a questão do custo de capital em setores regulados, com base nas metodologias elaboradas por COUTINHO e OLIVEIRA (2003), ANEEL (2005 e 2006) e BRAGANÇA et al. (2006).

\subsection{Introdução}

Sob o ponto de vista econômico-financeiro, uma pergunta básica que uma empresa deve responder antes do investimento é: que taxa de retorno é possível obter? Ou: qual o mínimo retorno esperado para valer a pena não investir no mercado financeiro? A resposta não é tão fácil de se avaliar, pois estimar o possível retorno de um investimento não é direto e simples, mas uma saída que se tornou prática comum em boa parte das empresas do mundo foi a utilização do modelo WACC. E o que é o WACC? Quais são as suas características? Como calculá-lo?

O enfoque dado pelo WACC parte do princípio de que os investimentos das empresas são financiados simultaneamente por capital de terceiros e por capital próprio. De acordo com 
ROSS (1995), WACC é o custo total de relativo ao capital próprio e o capital de terceiros. Em outras palavras, ele é a média ponderada entre os custos gerados pelo capital próprio e pelo capital de terceiros e suas respectivas participações na estrutura de capital da empresa, conforme salienta PRATT (1999, in KAYO, 2002).

Por outro lado, PRATTT (1998) afirma que o custo de capital deve ser adequado a cada investimento específico, implicando que devem ser utilizados diferentes valores de WACC para cada área de negócio, linha de produto ou serviço oferecido pela empresa.

É melhor calcular o WACC de forma mais específica possível, restringindo-o a um setor especifico. Neste trabalho selecionou-se para análise o setor de telefonia fixa. Uma forma mais precisa ainda seria considerar um negócio específico dentro do setor, como por exemplo, para o caso de telefonia fixa, varejo de telefonia fixa ou rede fixa, conforme cita ANATEL (2005). Entretanto, para não perder o foco, não serão tratados nesta dissertação os negócios específicos.

De maneira geral, as variáveis utilizadas pelo WACC são o custo capital próprio, o custo de capital de terceiros, a estrutura de capital (razão entre a dívida e o capital total da empresa) e a taxa efetiva de impostos.

Vale ressaltar que, ao considerar o imposto de renda de pessoa jurídica, o custo apropriado do capital de terceiros deve ser calculado após o imposto de renda (ROSS, 1995), pois não há imposto sobre dívida.

\subsection{Formulação Tradicional do WACC}

A maneira mais clássica de apresentar o WACC (após os impostos) é a que sugere PRATT (1998, em KAYO, 2002), como observado na EQ. (19):

EQ. (19)

$$
W A C C=r_{E} \cdot \frac{E}{D+E}+r_{D} \cdot \frac{D}{D+E}(1-T)
$$

sendo

E: Capital próprio (Patrimônio líquido ou Equity). 
D: Capital de terceiros (dívida).

$\mathrm{r}_{\mathrm{E}}$ : Custo de capital próprio.

$\mathrm{r}_{\mathrm{D}}$ : Custo de capital de terceiros.

T: Imposto de renda sobre pessoa jurídica mais contribuição social sobre lucro líquido.

Na maneira clássica, apresentada na equação anterior, o custo de capital próprio é calculado com base no CAPM. Entretanto, outros modelos foram criados com o mesmo propósito. É o caso do APT (Arbitrage Pricing Theory), proposto por ROSS (1976), e do DGM (Dividend Growth Model) elaborado inicialmente por GORDON (1962).

Sobre a EQ. (19) vale dizer ainda que a expressão $\mathrm{D} /(\mathrm{D}+\mathrm{E})$ é conhecida como estrutura de capital ou alavancagem, representando o nível de endividamento da empresa.

Quanto ao custo de capital de terceiros, como mensurá-lo? Uma maneira direta é através dos valores de financiamento explicitados em contratos específicos para cada empresa (KAYO, 2002). Neste caso, pode-se dizer que o custo de capital de terceiros é a taxa com que uma empresa consegue captar recursos financeiros.

Já BRAGANÇA et al. (2006) estimam o custo de capital de terceiros com base na soma da taxa do ativo livre de risco, risco de crédito e risco país. ANEEL (2006), por outro lado, procura estimar o custo financeiro com base na Taxa de Juros de Longo Prazo (TJLP) e no Índice Nacional de Preços ao Consumidor Amplo (IPCA). Como será visto adiante, ambos encontram, entretanto, custos muito próximos.

A existência da expressão (1-T) pode causar um pouco de estranheza em um primeiro momento. Mas ela existe simplesmente pelo fato de que em diversos países, como o Brasil e os EUA, por exemplo, não há pagamento de imposto sobre dívidas, o que implica a inexistência de custo sobre esta parcela de capital. Daí a subtração que se faz na parte direita da equação. Para o caso do Brasil, o valor de T é 34\%.

Para entender o WACC é interessante observar um exemplo. Considere uma empresa brasileira que apresenta uma estrutura de capital de 30\%, custo de capital próprio de 10\% a.a. e custo de capital de terceiros de 20\% a.a. Sabendo que o valor de T no Brasil é de 34\%, qual seria o custo de capital total? Para isso basta aplicar a EQ. (19). WACC $=10 \% \times 70 \%+20 \% \mathrm{x}$ 
$30 \%$. 34\% = 9\% a.a. Então, o custo de capital para esta empresa seria de 9\%, ou seja, para que um negócio seja rentável, a empresa deve conseguir um retorno maior do que $9 \%$.

Finalmente, embora o WACC seja a formulação mais utilizada para o cálculo do custo de capital, quando o assunto são os setores regulados, não há um consenso sobre a melhor maneira de aplicá-lo. Diversos trabalhos desenvolveram o tema propondo adaptações específicas para cada análise. COUTINHO e OLIVEIRA (2003) elaboraram uma metodologia, utilizada por ANEEL (2005), para o setor de distribuição de energia elétrica do Brasil, e por ANEEL (2006), para o setor de transmissão de energia elétrica do Brasil. E o IPEA, através de BRAGANÇA et al. (2006), considerou o caso específico da telefonia. Nos próximos dois itens estas metodologias para setores regulados serão vistas com mais detalhes.

\subsection{Metodologia ANEEL}

Primeiramente, por que utilizar uma metodologia do setor elétrico em telecomunicações? O motivo é que os setores de energia elétrica e telecomunicações apresentam diversas semelhanças que podem ser aproveitadas: ambos são regulados; são setores de infra-estrutura básica; apresentam um alto custo fixo para instalação de suas redes e um baixo custo marginal na prestação dos serviços, entre outros. Outro motivo é que ainda há poucas metodologias para setores regulados, sendo necessário aproveitar as vantagens das poucas existentes.

De maneira geral, a fundamentação das metodologias descritas em ANEEL (2005 e 2006) é igual. As maiores diferenças se referem aos períodos utilizados como referência e às especificidades dos setores distribuição e transmissão de energia elétrica. Aqui será dada uma maior ênfase em ANEEL (2006).

Para o caso do custo de capital, a ANEEL utilizou o WACC tradicional (após impostos), descrito na EQ. (19). A novidade acrescentada são os outros riscos considerados como, por exemplo, o regulatório, o cambial e o risco país. O acréscimo do risco regulatório deve-se ao argumento de que o modelo de regulação de energia elétrica do Brasil (regulação por incentivos através do modelo Price Cap) apresenta mais riscos do que outros modelos (p. ex., regulação por taxa de retorno, utilizada nos EUA). 
Nos próximos itens serão vistos os principais parâmetros utilizados por ANEEL (2006) no cálculo do WACC.

\subsubsection{Custo de Capital Próprio}

A próxima equação apresenta a forma de calcular o custo de capital próprio. No caso das metodologias ANEEL (2005 e 2006), utilizou-se o CAPM tradicional. Neste trabalho será utilizado o modelo genérico $\mathrm{G}_{\mathrm{w}}-\mathrm{CAPM}$, com o intuito de comparar os custos de capitais obtidos para cada um dos pesos w considerados.

A EQ. (20) descreve o cálculo do custo de capital próprio $\left(\mathrm{r}_{\mathrm{Ei}}\right)$ utilizado pela ANEEL:

EQ. (20)

$$
r_{E_{i}}=r_{f}+\beta_{i}\left(\mu_{M}-r_{f}\right)+r_{r}
$$

sendo

$\mathrm{r}_{\mathrm{f}}$ taxa do ativo livre de risco

$\beta_{\text {i: }}$ beta do setor regulado

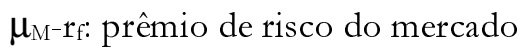

$\mathrm{r}_{\mathrm{r}}$ : outros prêmios de risco conforme EQ. (21).

Com o intuito de calcular o custo de capital para um setor regulado no Brasil são incorporados alguns prêmios de riscos adicionais, associados a peculiaridades do mercado local. Assim, entram na equação anterior o prêmio de risco Brasil $\left(\mathrm{r}_{\mathrm{B}}\right)$, risco cambial $\left(\mathrm{r}_{\mathrm{x}}\right)$ e o risco regulatório $\left(\mathrm{r}_{\mathrm{R}}\right)$, conforme a EQ. (21):

EQ. (21)

$$
r_{E_{i}}=r_{f}+\beta_{i}\left(\mu_{M}-r_{f}\right)+r_{B}+r_{x}+r_{R}
$$

Onde

$\mathrm{r}_{\mathrm{B}}$ : risco País ou risco Brasil, calculado pela EQ. (22);

$\mathrm{r}_{\mathrm{x}}$ : risco cambial;

$\mathrm{r}_{\mathrm{R}}$ : risco regulatório. 
Sem entrar em detalhes ${ }^{5}$, apresenta-se a seguir apenas a equação de cálculo do risco Brasil $\left(\mathrm{r}_{\mathrm{B}}\right)$ ou risco país:

EQ. (22)

$$
r_{B}=r_{s}-r_{c}^{B}
$$

Sendo

rs: prêmio de risco soberano;

$\mathbf{r}_{c}^{\mathrm{B}}$ : prêmio de risco de crédito das distribuidoras de energia elétrica do Brasil.

\section{- Ativo Livre de Risco}

No cálculo do ativo livre de risco considerou-se que uma boa referência é o Título do Tesouro dos EUA (USTB10) com vencimento em 10 anos entre os anos de 1928 e 2004. Calculando o retorno médio do título ANEEL (2006) encontrou o valor de 5,27\%a.a.

\section{- Beta}

De acordo com a ANEEL (2006) o mercado local não é um mercado maduro para aplicar o CAPM. Os motivos alegados que inviabilizam a utilização são:
a. qualidade e quantidade das informações não o permitem;
b. mercados de capitais não são amadurecidos;
c. séries de tempo não são suficientemente extensas;
d. fortes desequilíbrios macroeconômicos geram altas volatilidades dos papéis;
e. tem-se baixa liquidez em muitos casos, etc.

\footnotetext{
${ }^{5}$ Mais detalhes sobre o cálculo do prêmio de risco Brasil, soberano e regulatório podem ser vistos em ANEEL (2005 e 2006).
} 
Com o intuito de contornar esse problema, COUTINHO e OLIVEIRA (2003) apresentaram uma solução, incorporada pela ANEEL, que é a utilização de um mercado maduro como referência - no caso o mercado dos EUA.

A idéia é utilizar como base as ações de diversas empresas do setor de energia elétrica dos EUA que sejam similares às brasileiras e montar uma carteira de empresas, através das quais se chega a um valor médio do Beta.

De maneira simplificada calculou-se o Beta alavancado das diversas empresas, tomando um período de 5 anos e utilizando os retornos mensais das ações.

Para desalavancar o Beta utilizou-se a EQ. (23), com base na estrutura de capital de cada empresa i, obtendo o Beta desalavancado i.

EQ. (23)

$$
\beta_{i}^{\text {desalavancado }}=\beta_{i}^{\text {alavancado }}\left(\frac{E_{i}}{E_{i}+D_{i}\left(1-t_{i}\right)}\right)
$$

onde

$\beta_{i}^{\text {alavancado }}$ : beta alavancado para cada uma das empresas i dos EUA.

$E_{i:}$ Capital próprio da empresa i.

$\mathrm{D}_{\mathrm{i}}$ : Capital de terceiros da empresa $\mathrm{i}$.

$\mathrm{t}_{\mathrm{i}}$ alíquota efetiva de impostos do mercado dos EUA.

Para calcular o Beta desalavancado médio basta calcular a média dos Betas conforme a EQ. (24):

EQ. (24)

$$
\beta^{\text {desalavancado }}=\left(\frac{\sum_{i=1}^{I} \beta_{i}^{\text {desalavancado }}}{I}\right)
$$

Finalmente, para realavancar basta fazer o inverso da desalavancagem. Mas com a ressalva de que agora é preciso utilizar uma estrutura de capital (relação entre dívida e capital 
total empregado - D/(D+E)) adequada para o setor considerado, no caso de ANEEL, o setor de energia elétrica, de acordo com a EQ. (25):

EQ. (25)

$$
\beta_{i}^{\text {realavancado }}=\beta^{\text {desalavancado }}\left(\frac{E+D(1-T)}{E}\right)
$$

Sendo

$\beta_{i}^{\text {realavancado }}$ : beta realavancado para o mercado do Brasil.

$\beta_{i}^{\text {desalavancado }}$ : beta desalavancado calculado pela EQ. (24).

$\mathrm{E}_{\mathrm{i}}$ : Capital próprio da empresa i.

$\mathrm{D}_{\mathrm{i}}$ : Capital de terceiros da empresa i.

T: alíquota efetiva de impostos do Brasil.

No caso desta dissertação é necessário utilizar uma estrutura de capital adequada para o mercado local de telefonia fixa. Para uma estrutura de capital de 55\%, o valor final encontrado para o Beta do setor de distribuição de energia elétrica foi 0,289. É de se esperar que o beta do setor de telecomunicações seja maior do que este valor, uma vez que é mais vulnerável ao risco por ser um mercado mais imprevisível.

\section{- Prêmio de Risco de Mercado}

O prêmio de risco de mercado utilizado foi de 6,53\% a.a., sendo o cálculo feito com base na subtração entre a taxa do ativo livre de risco (USTB10) e a média histórica do retorno do mercado de referência (S\&P500) entre os anos de 1928 e 2004.

\section{- Risco País}

Como já foi adiantado pela EQ. (22), o risco País é calculado por ANEEL (2006) como a diferença entre o risco soberano e o risco de crédito das distribuidoras de energia elétrica do Brasil. 
$\mathrm{Na}$ apuração do risco soberano utilizou-se a série histórica diária do índice Emerging Markets Bonds Index do Brasil (EMBI+BR) de janeiro de 1995 a dezembro de 2004, resultando no valor médio de $8,47 \%$ a.a.

Já no cálculo do prêmio de risco de crédito Brasil, foram selecionadas empresas com classificação de risco B1 que tinham série de títulos de longo prazo com liquidez desde 1996. Com base na média dos spreads dessas empresas chegou-se ao valor de 4,50\% a.a

Portanto, o prêmio de risco País ou risco Brasil é igual a 3,97\% a.a.

\section{- Risco Cambial}

Embora muito discutível, a ANEEL entende que deve haver no cálculo do custo de capital um prêmio de risco cambial. A motivação para isso seria o fato de existir um risco nas movimentações financeiras que envolvam troca de moeda.

No cálculo as variáveis utilizadas levam em conta o spread do cambio no mercado futuro e a expectativa de desvalorização cambial. O valor encontrado, tendo como base dados mensais da BMF entre julho de 1999 e junho de 2002, foi de 2\% a.a. Embora defasado, ANEEL (2006) utilizou este mesmo prêmio para a revisão de tarifas do ano de 2006 da concessionária de transmissão de energia elétrica da empresa de transmissão de energia CTEEP.

\section{- Risco Regulatório}

Entende-se que o valor de Beta reflete o modelo regulatório adotado em cada país. Dessa forma, a princípio, não seria necessário adotar um prêmio de risco regulatório. Entretanto, como o modelo de regulação adotado no Brasil para o setor de energia elétrica (Price Cap) é mais arriscado que o modelo dos EUA (taxa de retorno), a ANEEL empregou uma metodologia específica para calcular o risco adicionado pelo modelo regulatório mais inseguro.

Finalmente, na Tabela (2) são apresentados os valores e uma breve descrição dos principais parâmetros utilizados no cálculo do custo de capital próprio. 


\begin{tabular}{lcl}
\hline Parâmetro & Taxa anual & Descrição \\
\hline Taxa Ativo Livre de Risco & $5,27 \%$ & $\begin{array}{l}\text { Taxa de retorno médio do USTB10 entre 1928 e } \\
2004\end{array}$ \\
\hline Risco do Negócio e Financeiro & $1,89 \%$ & $\begin{array}{l}\text { Risco da empresa ou setor em relação ao índice de } \\
\text { mercado }\end{array}$ \\
\hline Prêmio de Risco de Mercado & $6,53 \%$ & $\begin{array}{l}\text { Diferença média entre S\&P500 e USTB entre 1928 e } \\
2004\end{array}$ \\
\hline Beta & 0,289 & $\begin{array}{l}\text { Beta médio para o setor de distribuição de energia do } \\
\text { Prêmios por outros riscos }\end{array}$ \\
\hline Risco Cambial & $7,04 \%$ & Soma dos riscos cambial, regulatório e País \\
\hline Risco Regulatório & $2,00 \%$ & Spread do câmbio no Mercado futuro (BMF) \\
\hline Prêmio de Risco País & $1,07 \%$ & Risco do modelo brasileiro em relação ao dos EUA \\
\hline Custo de Capital Próprio & $3,97 \%$ & Diferença entre o risco soberano e o risco de crédito \\
Nominal & $14,20 \%$ & Custo do capital próprio considerando a inflação \\
\hline Custo de Capital Próprio Real & $11,46 \%$ & Custo de capital próprio final descontado a inflação \\
\hline Tabela (2) Estimativa do Custo de Capital Próprio obtido por ANEEL (2006) para o setor de \\
energia elétrica do Brasil.
\end{tabular}

\subsubsection{Custo de Capital de Terceiros}

Voltando à EQ. (19), o termo referente ao custo de capital de terceiros ( $\mathrm{r}_{\mathrm{D}}$ ) é também desmembrado em diversos outros termos conforme a EQ. (26).

EQ. (26) $\quad r_{D}=r_{f}+r_{c}+r_{B}+r_{x}$

Onde

$r_{f}$ taxa do ativo livre de risco.

$\mathrm{r}_{\mathrm{c}}$ : prêmio de risco de crédito do setor em análise.

$\mathrm{r}_{\mathrm{B}}$ : risco Brasil.

$\mathrm{r}_{\mathrm{x}}$ risco cambial. 
A equação anterior é sugerida por COUTINHO e OLIVEIRA (2003) e utilizada por ANEEL (2005). Entretanto, ANEEL (2006) considera outra estrutura de cálculo, tomando por base a taxa da TJLP e do IPCA.

Um resumo com os valores utilizados e uma breve descrição da metodologia de cálculo pode ser vista na Tabela (3):

\begin{tabular}{ccc}
\hline Parâmetro & $\begin{array}{c}\text { Taxa } \\
\text { anual }\end{array}$ & Metodologia de Cálculo \\
\hline Taxa Ativo Livre de Risco & $\mathrm{N} / \mathrm{A}$ & $\mathrm{N} / \mathrm{A}$ \\
\hline Prêmio de Risco de Crédito & $\mathrm{N} / \mathrm{A}$ & $\mathrm{N} / \mathrm{A}$ \\
\hline Prêmio de Risco País & $\mathrm{N} / \mathrm{A}$ & $\mathrm{N} / \mathrm{A}$ \\
\hline Custo de Capital de Terceiros & $11,25 \%$ & Cálculo com base na TJLP e IPCA \\
\hline
\end{tabular}

Custo de Capital de Terceiros Real $\quad 8,58 \%$

Tabela (3) Estimativa do Custo de Capital de Terceiros obtido por ANEEL (2006) para o setor de energia elétrica do Brasil

\subsubsection{Estrutura de Capital}

A ANEEL desenvolveu uma metodologia específica para calcular a estrutura de capital ótima para o setor. Mais detalhes podem ser vistos em ANEEL (2006). Um dos valores obtidos para empresas empresas análogas às concessionárias de telecomunicações foi o de $55 \%$, isto é, as empresas de distribuição possuem cerca de 55\% do capital total financiado por terceiros.

\subsubsection{Taxa efetiva de Impostos}

Com relação à taxa efetiva de impostos utilizada, ela é a mesma para todas as metodologias: 34\%.a.a

No próximo item será abordada a metodologia desenvolvida pelo IPEA, por meio de BRAGANÇA et al. (2006). 


\subsection{Metodologia IPEA}

De maneira geral, a formulação desenvolvida por BRAGANÇA et al. (2006) segue o modelo tradicional do WACC após impostos, conforme apresentado na EQ. (27):

EQ. (27)

$$
W A C C=\left(\frac{E}{E+D}\right) r_{E}+(1-t)\left(\frac{D}{E+D}\right) r_{D}
$$

onde:

$\mathrm{r}_{\mathrm{E}}=$ custo de capital próprio;

$\mathrm{r}_{\mathrm{D}}=$ custo de capital de terceiros;

$\mathrm{D}=$ capital de terceiros;

$\mathrm{E}=$ capital próprio;

$\mathrm{D} /(\mathrm{E}+\mathrm{D})=$ estrutura de capital; $\mathrm{e}$

$\mathrm{t}=$ alíquota efetiva de impostos.

\subsubsection{Custo de Capital Próprio}

Na justificativa para o uso do CAPM, BRAGANÇA et al. (2006) se apóia em um relatório da Andersen Management International. (AMI,2003), mostrando que os países mais importantes da Europa utilizam tal modelo, conforme tabela constante no Anexo II. A formulação matemática utilizada está resumida na EQ. (28).

EQ. (28)

$$
r_{E}=r_{f}+\beta\left(r_{m}-r_{f}\right)+r_{P}+r_{r e g}
$$

sendo

$\mathrm{r}_{\mathrm{f}}$ :taxa do ativo livre de risco;

$\beta$ : índice de risco Beta;

$\mathrm{r}_{\mathrm{m}}$ : retorno do mercado;

$\mathrm{r}_{\mathrm{m}}-\mathrm{r}_{\mathrm{f}}$ : prêmio de risco de mercado;

$\mathrm{r}_{\mathrm{p}}$ : prêmio de risco país;

$\mathrm{r}_{\text {reg }}$ : prêmio de risco regulatório. 


\section{- Ativo Livre de Risco}

Na formulação do ativo livre de risco BRAGANÇA et al. (2006) utilizou também o título do governo dos EUA com prazo de 10 anos até o vencimento, tendo uma duration de aproximadamente 8 anos (USTB10). A premissa considerada para esta escolha é a de que um projeto em telecomunicações tem retorno de longo-prazo. Logo o prazo do título representaria bem o setor. A taxa considerada foi a de 5,27\% a.a., obtida pela taxa média do título entre janeiro de 1995 e junho de 2005.

\section{- Beta}

Para determinar o valor de Beta ideal para o setor de telecomunicações no Brasil a metodologia escolheu um valor médio mundial entre as principais operadoras de telefonia fixa e móvel. Como o Beta calculado é o alavancado, foi necessário, então, desalavancá-lo pela estrutura de capital de cada empresa, da mesma maneira feita por ANEEL (2006), conforme a EQ. (23).

Em seguida foi feita uma média entre os valores desalavancados, chegando a um valor médio de Beta, do mesmo modo que a EQ. (24). O próximo passo, finalmente, foi realavancar o Beta médio para o setor em estudo, no caso telecomunicações do Brasil. A realavancagem foi feita com base na estrutura de capital média do setor de telecomunicações do Brasil, da mesma forma que a EQ. (25).

\section{- Prêmio de Risco de Mercado}

Para calcular o prêmio de risco do mercado utilizou-se a diferença média entre o título do Tesouro dos EUA de 10 anos de vencimento (USTB10) e o índice S\&P 500 entre os meses de janeiro/2000 e junho/2005. O valor obtido foi de 5,91\% a.a.

\section{- Risco País}

Bragança et al. (2006) utiliza como proxy para o risco país o índice EMBI+ (Emerging Markets Bond Index - stripped spreads) calculado pelo JP Morgan. O autor afirma que índice 
EMBI equivale ao retorno total de títulos denominados em dólar relativos à renegociação da dívida externa brasileira (Bradies) nos mercados emergentes e que satisfazem a uma série de critérios de liquidez. O valor obtido foi de 8,32\% a.a. entre janeiro/2000 e junho/2005.

\section{- Risco Cambial}

O risco cambial é citado em setores regulados do Brasil por COUTINHO e OLIVEIRA (2003). De acordo com o autor seria o prêmio de risco que deve ser inserido no custo de capital próprio devido às variações cambiais.

Embora ANEEL (2006) utilize um premio de risco cambial de 2\%, BRAGANÇA et al (2006), entretanto, rejeitam este prêmio alegando três motivos:

a) o índice utilizado no reajuste de tarifas do setor (IGP-DI) já considera os efeitos das variações cambiais, repassando, portanto, "às tarifas os efeitos das variações cambiais e, por esse motivo, poderia ser argumentado que o prêmio de risco cambial não deve ser remunerado no custo médio ponderado de capital estimado pelo regulador por não apresentar risco adicional para os investidores". No caso do setor de telecomunicações o atual índice utilizado é o Índice Setorial de Telecomunicações (IST), uma composição de diversos outros índices do mercado, entre eles, o IGP-DI. Continuaria, assim, valendo o argumento anterior.

b) O fato de o Brasil apresentar um mercado desenvolvido em mecanismos de proteção cambial (swaps, futuros, opções, etc) leva a questionar se o câmbio realmente constitui um risco não-diversificável.

c) Ainda que se considere importante o acréscimo de um prêmio relativo ao risco cambial, em muitos casos "as metodologias existentes são pouco robustas para serem aplicadas no âmbito da regulação".

Seguindo o autor anterior, neste trabalho não será considerado o risco cambial.

\section{- Risco Regulatório}

Este risco seria o risco de se investir em um país onde o regime regulatório é mais arriscado. Para o caso do setor elétrico, por exemplo, enquanto os EUA utilizam um regime de regulação por taxa de retorno, no Brasil é utilizado o Price-cap, que seria um pouco mais 
arriscado. Assim, seria necessário um prêmio de risco em países com regulação de tarifas mais arriscada.

Neste sentido, COUTINHO e OLIVEIRA (2003) estabelecem que o risco regulatório é igual à diferença entre o beta das distribuidoras subordinadas ao regime de tetos tarifários inglês (mais arriscado e similar ao modelo brasileiro para a distribuição de energia elétrica) e o beta das distribuidoras dos EUA (subordinadas ao regime de taxa de retorno ou rate-of-return).

BRAGANÇA et al. (2006), no entanto, propõem em seu trabalho para o setor de telecomunicações que o risco regulatório seja desconsiderado, uma vez que o regime brasileiro é igual ao dos EUA. Ele ressalta que existe um risco adicional causado pela adoção do LRIC mas que ainda não há uma metodologia para o seu cálculo. Na Tabela (4) são apresentados os valores e a metodologia detalhada para cada uma dos parâmetros utilizados por BRAGANÇA et al (2006).

\begin{tabular}{|c|c|c|}
\hline Parâmetro & $\begin{array}{l}\text { Taxa } \\
\text { anual }\end{array}$ & Metodologia de cálculo \\
\hline Taxa Ativo Livre de Risco & $5,35 \%$ & Título do Tesouro dos EUA - USTB10 (jan95-jun05) \\
\hline $\begin{array}{l}\text { Risco do Negócio e } \\
\text { Financeiro }\end{array}$ & $7,12 \%$ & Multiplicação entre Beta e o prêmio de risco de mercado \\
\hline Prêmio de Risco de Mercado & $5,93 \%$ & $\begin{array}{l}\text { Retorno do mercado (S\&P500) em relação ao retorno do } \\
\text { título do tesouro dos EUA ( jan00-jun05) }\end{array}$ \\
\hline Beta & 1,20 & $\begin{array}{l}\text { Média dos betas das empresas de telefonia de todo o } \\
\text { mundo }\end{array}$ \\
\hline Prêmios por outros riscos & $8,32 \%$ & Neste caso foi considerado somente o risco País. \\
\hline Risco Cambial & - & - \\
\hline Risco Regulatório & - & - \\
\hline Prêmio de Risco País & $8,32 \%$ & $\begin{array}{l}\text { Spread entre EMBI+BR e título similar dos EUA } \\
\text { (jan00/jun05) }\end{array}$ \\
\hline $\begin{array}{l}\text { Custo de Capital Próprio } \\
\text { Nominal }\end{array}$ & $20,79 \%$ & Para concessionárias de telefonia do Brasil \\
\hline Custo de Capital Próprio Real & $17,78 \%$ & Custo de Capital Próprio Nominal descontada a inflação \\
\hline
\end{tabular}




\subsubsection{Custo de Capital de Terceiros}

De maneira geral o custo de capital de terceiros considerado pelos autores leva em conta três parâmetros, conforme a EQ. (29):

EQ. (29) $\quad r_{D}=r_{f}+r_{C}+r_{P}$

sendo

$\mathrm{r}_{\mathrm{D}}=$ custo de capital de terceiros;

$\mathrm{r}_{\mathrm{f}}=$ taxa do ativo livre de risco;

$\mathrm{r}_{\mathrm{C}}=$ prêmio de risco de crédito;

$\mathrm{r}_{\mathrm{p}}=$ prêmio de risco país.

Mais detalhes sobre os valores utilizados e a metodologia de cada parâmetros são apresentados na Tabela (5).

\begin{tabular}{lrl}
\hline \multicolumn{1}{c}{ Parâmetro } & $\begin{array}{c}\text { Taxa } \\
\text { anual }\end{array}$ & \multicolumn{1}{c}{ Metodologia de Cálculo } \\
\hline Taxa Ativo Livre de Risco & $5,35 \%$ & USTB10 (jan05-jun05) \\
\hline Prêmio de Risco de Crédito & $3,25 \%$ & $\begin{array}{l}\text { Spread do melhor rating de empresas de telefonia do Brasil } \\
\text { (jan00-jun05) }\end{array}$ \\
\hline Prêmio de Risco País & $8,32 \%$ & $\begin{array}{l}\text { Spread entre EMBI+BR e título similar dos EUA jan00- } \\
\text { jun05 }\end{array}$ \\
\hline Custo de Capital de Terceiros & $16,92 \%$ & Soma da Taxa livre de risco, risco de crédito e risco país \\
Nominal & $14,01 \%$ Valor nominal descontada a inflação \\
\hline Custo de Capital de Terceiros Real & Estimativa do Custo de Capital de Terceiros obtido por BRAGANÇA et al (2006) para \\
\hline Tabela (5) & o setor de telecomunicações do Brasil
\end{tabular}




\subsubsection{Estrutura de Capital}

Há uma estrutura de capital ótima que minimiza o custo médio ponderado de capital. Entretanto, há muita discussão sobre o valor ideal a ser utilizado. Nesta metodologia foi empregada uma estrutura de capital média das diversas empresas brasileiras do setor. $\mathrm{O}$ valor médio encontrado foi de $38 \%$.

\subsubsection{Taxa Efetiva de Impostos}

$\mathrm{Na}$ taxa efetiva de impostos do Brasil foi considerado o valor de $34 \%$, composto por 25\% da alíquota de Imposto de Renda e 9\% da CSLL (Contribuição Social sobre o Lucro Líquido). No caso da desalavancagem realizada nas diversas operadoras de telecomunicações do mundo foi considerada a taxa efetiva de cada país, como era de se esperar. 


\section{Metodologia}

Neste Capítulo serão tecidos alguns comentários sobre os diversos parâmetros utilizados na elaboração da Metodologia: mercado utilizado, período de análise, variáveis envolvidas, índices elaborados e a avaliação de desempenho dos modelos analisados.

\subsection{Metodologia para o CAPM e modelos variantes}

\subsubsection{Mercado}

O uso do modelo $\mathrm{CAPM}^{6}$ ou suas variantes encontra aplicação direta no cálculo do custo de capital. Antes de aplicar o CAPM, porém, é necessário definir o mercado a ser utilizado, isto é, a bolsa de valores mais condizente com o estudo em questão.

Sendo possível é melhor utilizar o próprio mercado local. No caso brasileiro, entretanto, há alguns empecilhos, conforme cita CAMACHO (2004): falta de liquidez do mercado, insuficiência de dados históricos, além de o mercado não permitir consistência no cálculo do custo de capital.

Tendo em vista esses problemas, adotou-se como referência o mercado dos EUA, que apresenta maior liquidez e abundantes dados históricos. Ainda, assim, devido à recente

\footnotetext{
${ }^{6}$ As formulações feitas neste capítulo para o CAPM também se aplicam ao $\mathrm{G}_{\mathrm{w}}$-CAPM.
} 
privatização, o período histórico das ações de telecomunicações do Brasil é curto, começando no final da década de 90. A bolsa de valores escolhida foi a New York Stock Exchange (NYSE).

\subsubsection{Período de análise}

Outros pontos importantes na análise do CAPM são o período da análise e a média a ser empregada no cálculo do retorno médio das ações e índices. A escolha do período utilizado no CAPM é fundamental, pois períodos curtos refletem demasiadamente a conjuntura, enquanto períodos longos podem refletir regimes econômicos muito distintos dos que se verifica no médio prazo (BRAGANÇA et al, 2006). Neste trabalho utilizou-se o período de 5 anos como base para o cálculo do Beta, e o período de 1928-2004 para achar um valor médio para o prêmio de risco e o ativo livre de risco. A média empregada foi a aritmética.

\subsubsection{Variáveis}

Com relação às variáveis envolvidas diretamente no cálculo do CAPM (D-CAPM ou $\mathrm{G}_{\mathrm{w}}-\mathrm{CAPM}$ ), as principais são: ativo livre de risco, risco (beta) e retorno das ações, e o prêmio de risco. Nos próximos itens será abordada cada uma delas.

\section{- Ativo livre de risco}

A maturidade do ativo livre de risco deve ser condizente com o setor estudado. No caso de telefonia fixa, o período de retorno dos investimentos é de longo-prazo. Sendo assim, adotou-se o título do Tesouro dos EUA com vencimento de 10 anos e maturidade em torno de 8 anos, representado pelo símbolo USTB10. O valor médio anual obtido foi 5,30\% no período de 1995 a 2005.

\section{- Índice de Mercado}

O índice utilizado como proxy para o mercado foi o S\&P500. No cálculo do prêmio de risco de mercado considerou-se a média da diferença entre USTB10 e S\&P500 no período 1995 a 2005, resultando no valor anual de 5,91\%. 


\section{- Retorno}

Os retornos das ações e dos índices utilizados foram calculados com base em cotações obtidas das seguintes fontes: YahooFinance, Economática e Reuters. O cálculo do retorno de uma ação i no tempo t foi realizado com base na razão entre o Preço no mês (dia/ano) atual e o preço no mês (dia/ano) anterior, conforme a EQ. (30):

$$
\text { EQ. (30) } \quad R_{i, t}=\frac{P_{i, t}}{P_{i, t-1}}-1
$$

onde

$\mathrm{P}_{\mathrm{i}, \mathrm{t}}$ : preço da ação i no período t.

$\mathrm{P}_{\mathrm{i}, \mathrm{t}-1}$ : preço da ação i no período $(\mathrm{t}-1)$.

Em todo o trabalho foi considerado que a média aritmética dos retornos passados é um bom estimador para o retorno esperado.

Finalmente, um resumo da freqüência e do período utilizado é mostrado na Tabela (6). E um panorama das cotações das ações e índices utilizados neste trabalho pode ser visto em detalhes no Anexo I.

\begin{tabular}{ccc}
\hline Variáveis & frequência & Período \\
\hline Retorno & Mensal & nov/1998-out/2005 \\
$(\mathrm{TSP}, \mathrm{BRP}, \mathrm{TNE}, \mathrm{VZ}$, ATT, BLS, ITBR e ITEU) & & \\
\hline
\end{tabular}

Tabela (6) Detalhes da variável Retorno empregada na metodologia desenvolvida

Uma limitação das ações de telefonia do Brasil é o fato de não haver séries históricas longas, devido à recente privatização do mercado. Como se observa na tabela anterior, a data mais antiga existente é a de 1998. Com isso as séries são relativamente curtas (cerca de 7 anos). 
Entretanto, a maior restrição possível em termos de período seria com relação ao cálculo do Beta, que se recomenda calcular com um período mínimo de 5 anos. Mas como a série tem um período superior, esta restrição foi atendida.

\section{- $\quad$ Risco}

Para calcular o risco das ações foi considerado o parâmetro Beta (ou $G_{w}$-Beta para o CAPM generalizado). Suas principais características são o período de 5 anos e a freqüência mensal. Os parâmetros do CAPM foram calculados entre outubro/2003 e outubro/2005, sendo utilizado como base sempre o período móvel de 5 anos para cada valor. Exemplo: para o Beta de outubro/2003 foi utilizado o período de 5 anos anterior a outubro/2003; para novembro/2003 utilizou-se o período de 5 anos anterior a novembro/2003; e assim por diante.

Finalmente, uma última observação é com relação à metodologia utilizada. ROSS (1995) afirma que um dos maiores problemas com o Beta é que ele pode variar com o tempo. O autor quer dizer que se houver uma crise pontual em um determinado país ou empresa e o Beta for pontual, ele refletirá demasiadamente esta crise. Para evitar ou minimizar esse problema, calculou-se o Beta ao longo de um período de 25 meses. Na nova orientação a custos adotada pela Anatel, poderia ser utilizado o valor médio ao longo dos 25 meses ou outro período necessário.

Um resumo das características de $\mathrm{G}_{\mathrm{w}}$-Beta é apresentado na Tabela (7).

\begin{tabular}{ccc}
\hline Variáveis & Características & Período utilizado \\
\hline \multirow{2}{*}{$\mathrm{G}_{\mathrm{w}}$-Beta } & Calculado mensalmente a partir de out $/ 2003$, com base & out $/ 2003$-out $/ 2005$ \\
& nos 5 anos anteriores; & \\
\hline
\end{tabular}

\section{- Prêmio de Risco}

Para calcular o prêmio de risco considerou-se o retorno médio do S\&P500 e subtraiuse do retorno médio do USTB10, tomando o período base de 1995 a 2005. O resultado obtido 
foi a taxa anual de 5,91\%. Ao aplicar o modelo $G_{w}-C A P M$, esta taxa foi convertida de anual para mensal.

Um resumo com as principais características das variáveis e respectivos períodos é apresentado na Tabela (8).

\begin{tabular}{|c|c|c|c|c|c|}
\hline Ano & Índice S\&P500 & $\begin{array}{l}\text { Retorno } \\
\text { S\&P500 }\end{array}$ & $\begin{array}{c}\text { Retorno anual } \\
\text { médio S\&P500 } \\
(1995-2005)\end{array}$ & $\begin{array}{c}\text { Retorno diário } \\
\text { médio UST B10 } \\
(1995-2005)\end{array}$ & $\begin{array}{l}\text { Prêmio de risco } \\
\text { médio (1995-2005) }\end{array}$ \\
\hline 2005 & 1248,29 & $3,00 \%$ & \multirow{12}{*}{$11,21 \%$} & \multirow{12}{*}{$5,30 \%$} & \multirow{12}{*}{$5,91 \%$} \\
\hline 2004 & 1211,92 & $8,99 \%$ & & & \\
\hline 2003 & 1111,91 & $26,38 \%$ & & & \\
\hline 2002 & 879,82 & $-23,37 \%$ & & & \\
\hline 2001 & 1148,09 & $-13,04 \%$ & & & \\
\hline 2000 & 1320,28 & $-10,14 \%$ & & & \\
\hline 1999 & 1469,25 & $19,53 \%$ & & & \\
\hline 1998 & 1229,23 & $26,67 \%$ & & & \\
\hline 1997 & 970,43 & $29,78 \%$ & & & \\
\hline 1996 & 747,74 & $21,40 \%$ & & & \\
\hline 1995 & 615,93 & $34,11 \%$ & & & \\
\hline 1994 & 459,27 & - & & & \\
\hline
\end{tabular}

\subsection{4. Índices para o mercado local de telefonia fixa}

Para representar o mercado de telefonia fixa do Brasil, área escolhida para estudo, elaborou-se um índice de ações, cujo símbolo utilizado foi ITBR (Índice de Telefonia do Brasil). Ele é composto pelas três principais concessionárias do setor de telefonia fixa do Brasil que, provavelmente, serão qualificadas como empresas com PMS (Poder de Mercado Significativo) ${ }^{7}$ : Telefônica (símbolo TSP), Brasil Telecom (símbolo BRP), e Telemar (símbolo TNE). Na Tabela (9) é apresentado um resumo das características de composição do índice:

\footnotetext{
${ }^{7}$ Entre as empresas que possuem ações negociadas na Bolsa NYSE, as três empresas anteriores são as únicas que, provavelmente, serão classificadas como PMS para o mercado local de telefonia fixa.
} 


\begin{tabular}{cccc}
\hline Símbolo & Empresa & Composição de ITBR & Composição de ITBR-P \\
\hline TSP & Telefônica & 0,33 & 0,56 \\
\hline BRP & Brasil Telecom & 0,33 & 0,13 \\
\hline TNE & Telemar & 0,33 & 0,31 \\
\hline
\end{tabular}

Tabela (9) Características das ações e índices utilizados

A solução ideal seria compor um índice com um número maior de empresas, mas há poucas ações de empresas brasileiras de telefonia negociadas na bolsa NYSE.

Com relação à composição do ITEU e ITEU-P ela é mostrada no ANEXO IX.

\subsubsection{Avaliação de desempenho dos modelos variantes do CAPM}

A teoria CAPM pode ser usada para avaliar o desempenho de uma carteira de investimentos (COSTA e ASSUNÇÃO, 2005). Dois elementos importantes para isto são os índices de Jensen e de Sharp. O primeiro não considera na sua medida o risco do um ativo ou ação, enquanto o segundo chega a um valor de desempenho com base tanto no retorno médio como no risco envolvido (variância).

Outra forma de avaliação de carteiras é a comparação da estimativa com o valor real de mercado, calculando o erro quadrático médio ou a raiz do erro quadrático médio (REQM). Nos próximos dois itens serão descritos com mais detalhes os índices anteriores, ressaltando-se que nesta dissertação só será implementado o índice de Jensen e o REQM.

$\mathrm{Na}$ avaliação dos modelos que melhor estimam o retorno de ações considerou-se principalmente o REQM (Raiz do Erro Quadrático Médio). Adicionalmente, aplicou-se o índice de Jensen, conforme COSTA e ASSUNÇÃO (2005).

\section{- REQM}

A principal análise feita neste trabalho para avaliar o desempenho dos modelos é o REQM (Raiz do Erro Quadrático Médio), que mede o erro quadrático entre o valor real e o 
valor estimado por cada modelo. O valor real é calculado com base na média aritmética dos retornos dos últimos 5 anos (período igual ao do Beta).

Como este trabalho estimou valores para o período de outubro/2003 a outubro/2005, em um total de 25 meses, o REQM apresentado na próxima Seção é uma média ao longo dos 25 meses considerados. Quanto menor o valor de REQM melhor o modelo estima o valor real de mercado para a carteira analisada.

\section{- Índice de Jensen:}

Já o cálculo do índice de Jensen ( $\mathrm{J}$ ) de uma determinada ação se baseia na diferença entre o retorno médio real e o valor esperado pelo CAPM.

Para ilustrar matematicamente o Índice, seja novamente uma carteira P. O valor de Jensen para esta carteira, conforme COSTA e ASSUNÇÃO (2005), pode ser descrito pela EQ. (31):

EQ. (31)

$$
J=\hat{r_{P}}-r_{P}
$$

sendo

$\wedge$

$r_{P}$ : retorno médio da carteira $\mathrm{P}$, calculado pela média aritmética dos retornos passados;

$r_{P}$ : retorno esperado para a carteira $\mathrm{P}$ através do CAPM.

Uma outra maneira de escrever a equação anterior é através da EQ. (32):

EQ. (32)

$$
J=\hat{r_{P}}-\hat{r_{f}}-\beta_{R_{P}}\left(\hat{\mu_{M}}-\hat{r_{f}}\right)
$$

onde

$\mu_{M}$ : retorno médio do mercado; 
$r_{f}:$ retorno médio do ativo livre de risco; e

$\beta_{R_{P}}:$ Beta da carteira P.

Da equação anterior resultam três conclusões importantes:

- $\mathrm{J}>0 \rightarrow$ indica um retorno real acima do esperado;

- $\mathrm{J}<0 \rightarrow$ indica um retorno real abaixo do esperado;

- $\mathrm{J}=0 \rightarrow$ indica um retorno real igual ao esperado.

Portanto, valores positivos de $\mathrm{J}$ sugerem que o retorno observado foi acima do esperado, indicando um bom desempenho da carteira segundo esse critério. Valores negativos, por sua vez, indicam um desempenho abaixo do esperado. No Capítulo 4 será apresentado um gráfico com os valores desse índice. O desempenho do modelo será tão melhor quanto mais próximos os valores ficarem de zero.

Vale ressaltar, finalmente, que essa análise não considera o risco da carteira, comparando apenas a retorno observado com o seu valor teórico previsto pela fórmula do CAPM. Caso se queira considerar o risco da carteira é preciso utilizar o índice de Sharp ${ }^{8}$.

O cálculo do índice de Jensen (J) de um determinado ativo se baseia na diferença entre o retorno médio real desse ativo e o valor esperado pelo CAPM. Para ilustrar matematicamente o funcionamento deste índice, seja uma determinada ação i, com retornos representados por $\mathrm{R}_{\mathrm{i}}$, valor esperado representado por $\mathrm{r}_{\mathrm{i}}$, e retorno médio dado por $\hat{r}_{i}$, sendo $\hat{r}_{i}=\sum_{i=1}^{n} \frac{R_{i}}{n}$. Seja também o mercado, com retornos representado por $R_{M}$, com valor esperado $\mu_{M}$, e o retorno médio dado por $\hat{\mu}_{M}$, sendo $\hat{\mu}_{M}=\sum_{k=1}^{n} \frac{R_{M_{k}}}{n}$. Analogamente ao que foi feito para o mercado e para a ação i, são feitas considerações para o ativo livre de risco, sendo importante destacar somente que $\mathrm{r}_{\mathrm{f}}$ é o retorno para o ativo e $\hat{r}_{f}$ é o retorno médio.

${ }^{8} \mathrm{O}$ índice de Sharp pode ser visto em mais detalhes em COSTA e ASSUNÇÃO (2005). 
Portanto, de posse das considerações anteriores, pode-se escrever na EQ. (33) o índice de Jensen para uma ação i

EQ. (33)

$$
J=\hat{r}_{i}-r_{i}
$$

sendo

$\wedge$

$r_{i}$ é o retorno médio da ação i; e

$r_{i}$ é retorno esperado da mesma ação através do CAPM.

Outra maneira de escrever a equação anterior é através da EQ. (34):

EQ. (34)

$$
J=\hat{r}_{i}-\hat{r_{f}}-\beta_{R_{i}}\left(\hat{\mu_{M}}-\hat{r_{f}}\right)
$$

onde

$\hat{\mu_{M}}:$ retorno médio do mercado;

$\hat{r_{f}}$ : retorno médio do ativo livre de risco;

$\beta_{R_{i}}$ : risco da ação i.

Pela equação anterior pode-se concluir que $\mathrm{J}>0$ indica um retorno acima do esperado, enquanto $\mathrm{J}<0$ indica um retorno abaixo do esperado.

\subsection{Metodologia desenvolvida para o WACC}

A elaboração da metodologia utilizada nesta dissertação se baseou em ANEEL (2006) e BRAGANÇA et al. (2006), utilizando uma ou outra conforme a conveniência, e adaptando o período de cálculo de alguns parâmetros conforme a necessidade. De maneira geral, a maior inovação foi na forma de calcular o Beta, utilizando um valor médio ao longo de 25 meses. 
Nos próximos itens são apresentados cada uma dos parâmetros utilizados, entre eles: custo de capital próprio, custo de capital de terceiros, estrutura de capital e alíquota efetiva de impostos.

\subsubsection{Custo de Capital Próprio}

No cálculo do custo de capital próprio o modelo mais empregado é o CAPM. Como um dos objetivos principais desta dissertação é justamente analisar o modelo $\mathrm{G}_{\mathrm{w}}-\mathrm{CAPM}$, este modelo foi empregado no cálculo do custo de capital próprio. Obviamente, para $w=0,5$ ele estará descrevendo o próprio modelo CAPM.

Analisando as principais variáveis do modelo tem-se:

\section{- Beta}

Utilizando a metodologia empregada por ANEEL (2006) foram escolhidas algumas empresas do setor dos EUA como proxy para as empresas brasileiras, conforme a Tabela (10).

\begin{tabular}{cccccc}
\hline & $\mathbf{w}=\mathbf{0 , 0 0}$ & $\mathbf{w}=\mathbf{0 , 2 5}$ & $\mathbf{w}=\mathbf{0 , 5 0}$ & $\mathbf{w}=\mathbf{0 , 7 5}$ & $\mathbf{w}=\mathbf{1 , 0 0}$ \\
\hline Verizon & 1,46 & 1,24 & 0,96 & 0,89 & 1 \\
\hline AT\&T & 1,28 & 1,02 & 0,79 & 0,86 & 1,05 \\
\hline BLS & 1,49 & 1,3 & 1,06 & 1,02 & 1,13 \\
\hline
\end{tabular}

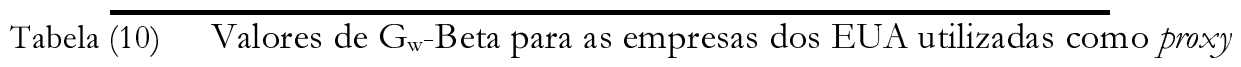

A inovação deste trabalho é o fato de calcular um valor médio de Beta ao longo dos anos para as operadoras acima ao longo de 25 meses, garantindo que ele não vai refletir uma situação pontual dos últimos anos. 


\section{- Prêmio de risco de mercado}

No cálculo do prêmio de risco de mercado foi empregada uma metodologia semelhante a de BRAGANÇA et al. (2006), com o período alterado para janeiro/1995 a dezembro/2005.

\section{- Ativo livre de risco}

A metodologia também é semelhante a de BRAGANÇA et al. (2006), mas com o período alterado para janeiro/1995 a dezembro/2005, em consonância com o período utilizado para o prêmio de risco de mercado.

\subsubsection{Custo de Capital de Terceiros}

Ao contrário de ANEEL (2006), BRAGANÇA et al. (2006) considera que o custo de capital de terceiros é bem estimado por três fatores: prêmio de risco de crédito, prêmio de risco país e a taxa do ativo livre de risco. Esta foi a forma utilizada neste trabalho, conforme detalhamento a seguir:

\section{- Prêmio de risco de crédito}

Considerou-se que uma boa maneira de estimar este prêmio é através do Spread do melhor rating de empresas de telefonia do Brasil entre janeiro/2000 e junho/2005, da mesma maneira que BRAGANÇA et. al (2006). O valor encontrado foi de 3,25\% a.a.

\section{- Prêmio de risco País}

Da mesma maneira que em BRAGANÇA et al (2006) utilizou-se o valor de 8,32\% a.a.

- Ativo Livre de risco

Da maneira semelhante a BRAGANÇA et al (2006) utilizou-se o valor de 5,30 \% a.a. A principal diferença está no período de cálculo: janeiro/1995 a dezembro/2005. 


\subsubsection{Estrutura de Capital}

$\mathrm{Na}$ estrutura de capital ótima considerou-se que um bom proxy é a média da estrutura das empresas do setor de telefonia celular e telefonia fixa. BRAGANÇA el al (2006) encontram um valor médio de 38\%, que foi utilizado neste trablalho.

\subsubsection{Taxa Efetiva de Impostos}

A taxa efetiva de impostos no Brasil é composta de $25 \%$ de imposto de renda e $9 \%$ de Contribuição Social sobre o Lucro Líquido (CSLL), totalizando 34\%.

\subsubsection{Avaliação de desempenho da metodologia}

Como já foi dito, o objetivo principal desta dissertação não é a metodologia para cálculo do custo de capital, mas analisar o desempenho do CAPM generalizado (Gw-CAPM). Neste sentido é que se elaborou a metodologia. Ele será útil para analisar se as diferenças ocasionadas pelo Gw-CAPM são significativas ou não em relação ao CAPM.

Outra maneira de se avaliar os resultados obtidos será compará-los com os valores de custo de capital obtidos por diversos outros trabalhos na área, tais como. Um fato importane em sua maioria, trabalhos práticos, como por exemplo, ABN-AMRO (2006), BRASCAN (2006), ACCENTURE e GT (2005) e BRAGANÇA et al (2006). É importante destacar aqui que três destes trabalhos são extremamente reais e práticos, pois foram desenvolvidos por empresas. Somente BRAGANÇA et al (2006) é acadêmico. Portanto, os valores obtidos nesta dissertação poderão ser comparados com trabalhos profissionais e acadêmicos. 


\section{RESUltados}

Neste Capítulo serão apresentados os resultados obtidos, divididos da seguinte forma: $G_{w}{ }^{-}$ Beta, $\mathrm{G}_{\mathrm{w}}-\mathrm{CAPM}$ e WACC.

\section{1. $\mathrm{G}_{\mathrm{w}}-$ Beta}

Aplicando a metodologia descrita no Capítulo anterior calcularam-se os valores de $\mathrm{G}_{\mathrm{w}}{ }^{-}$ Beta para $\mathrm{w}=0,0.25,0.50,0.75$ e 1 . Os valores médios ao longo do tempo, tanto para o ITBR como para o ITEU, podem ser vistos na Tabela (11):

\begin{tabular}{lccccc}
\hline & $\mathrm{w}=0,00$ & $\mathrm{w}=0,25$ & $\mathrm{w}=0,50$ & $\mathrm{w}=0,75$ & $\mathrm{w}=1,00$ \\
\hline ITBR & 2,033 & 1,992 & 2,043 & 2,170 & 2,249 \\
\hline ITEU & 1,343 & 1,157 & 0,941 & 0,930 & 1,043 \\
\hline
\end{tabular}

Tabela (11) Valores médios dos índices ITBR e ITEU

Já o comportamento de $G_{w}$-Beta ao longo do tempo para ITBR e ITEU pode ser visto na Figura 6 . 

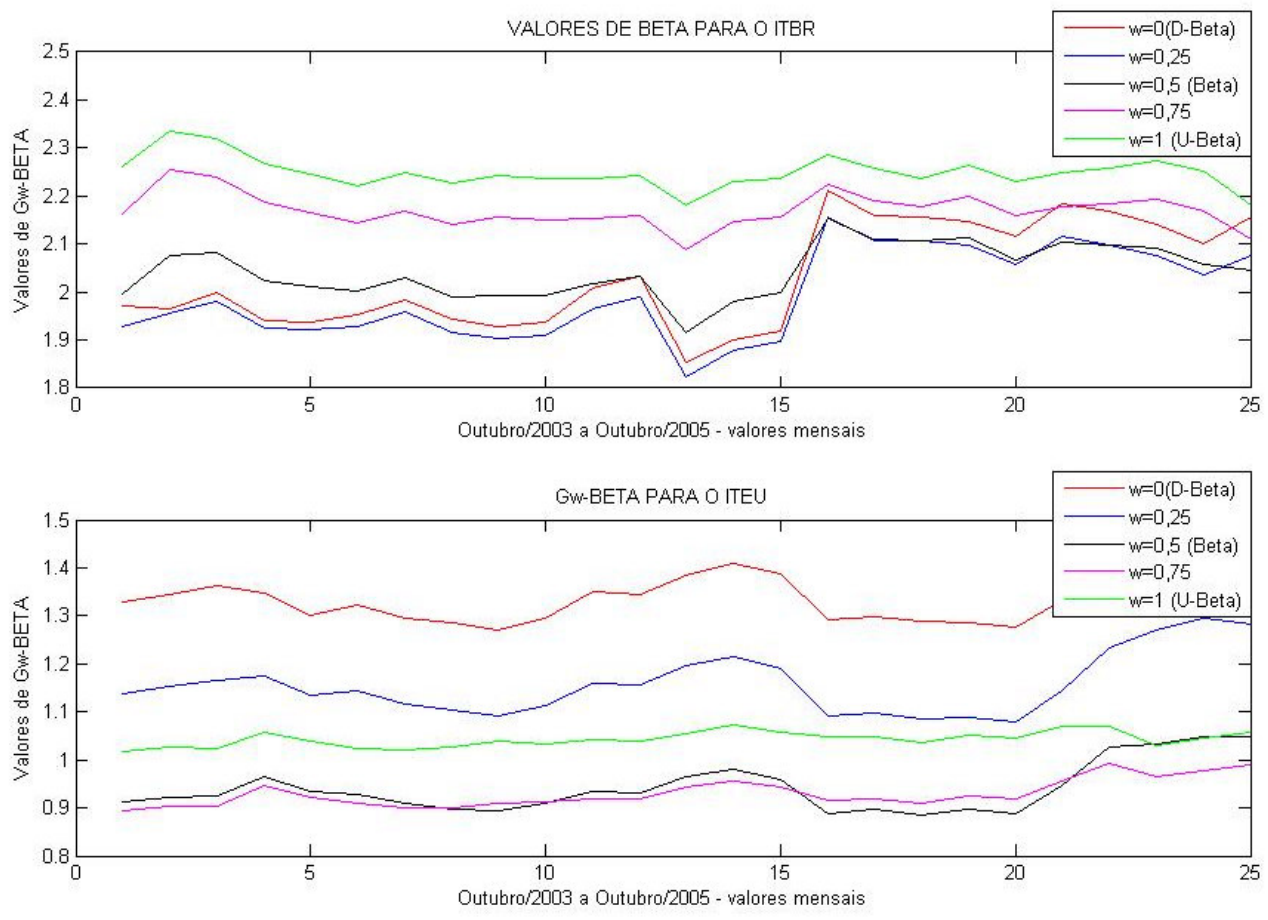

Figura 6 - Valores de $G_{w}$-Beta para os índices ITBR e ITEU

$\mathrm{Na}$ figura anterior é possível perceber visualmente que o beta do índice ITEU guarda uma regularidade maior ao longo do tempo em relação ao ITBR. Uma explicação para isso é a origem das empresas que estes índices estão representando: EUA e Brasil, respectivamente.

Embora não fique tão claro na Figura 6 , analisando a Tabela (11) constata-se que, na média, os valores de $G_{w}$-beta para o ITBR seguem a relação: $\left(G_{1,0^{-}}\right.$Beta $>G_{0,75^{-}}$Beta $>G_{0,5^{-}}$ Beta $>\mathrm{G}_{0}$-Beta $>\mathrm{G}_{0,25}$-Beta).

O maior valor de $G_{w}$-Beta, portanto, é dado por $G_{1,0}$-Beta (ou U-Beta), enquanto o menor é dado pelo $\mathrm{G}_{0,25}$-Beta.

Já para o ITEU os valores $G_{w}$-beta seguem a relação: $\left(G_{0}\right.$-Beta $>G_{0,25}$-Beta $>G_{1,0}-$ Beta $>\mathrm{G}_{0,5}-$ Beta $>\mathrm{G}_{0,75}$-Beta).

A relação anterior mostra que o maior valor de $G_{w}$-Beta é dado por $G_{0}$-Beta (ou UBeta), enquanto o menor é dado pelo $\mathrm{G}_{0,75}$-Beta. Dessa relação e da anterior, percebe-se que não há uma lógica na relação quantitativa entre os valores para cada peso w. 
Por outro lado, uma pergunta ainda permanece sem resposta: a ponderação dos índices pelo Market Cap influencia ou não os resultados? Para responder à pergunta basta analisar a os valores médios de ITBR-P e ITEU-P na Tabela (12)

\begin{tabular}{cccccc}
\hline & $\mathbf{w}=\mathbf{0 , 0 0}$ & $\mathbf{w}=\mathbf{0 , 2 5}$ & $\mathbf{w}=\mathbf{0 , 5 0}$ & $\mathbf{w}=\mathbf{0 , 7 5}$ & $\mathbf{w}=\mathbf{1 , 0 0}$ \\
\hline ITBR-P & 2,098 & 2,013 & 2,017 & 2,147 & 2,256 \\
\hline ITEU-P & 1,329 & 1,139 & 0,922 & 0,916 & 1,035 \\
\hline Tabela (12) & Valores médios dos índices ponderados ITBR-P e ITEU-P
\end{tabular}

$\mathrm{Na}$ tabela anterior constata-se que praticamente não há alteração na relação entre os parâmetros, seja do ITBR seja do ITEU.

De uma maneira geral, com relação aos valores de $G_{w}$-Beta, percebe-se que são altos para o caso do Brasil. BRAGANÇA et al.(2006), por exemplo, encontra o valor médio de 1,2 para o beta de empresas do setor de telecomunicações de todo o mundo. Neste trabalho foram encontrados valores acima de 2. A principal explicação para este fato é a freqüência de observações mensal (e não semanal ou diária) para os retornos das ações.

Uma questão a analisar ainda é se as variações do $G_{w}$-Beta são significativas em relação ao Beta do CAPM ou não. Na Tabela (13) são apresentadas essas variações em relação a $\mathrm{w}=0,5$.

\begin{tabular}{cccccc}
\hline Variação & $\mathbf{w}=\mathbf{0 , 0 0}$ & $\mathbf{w}=\mathbf{0 , 2 5}$ & $\mathbf{w}=\mathbf{0 , 5 0}$ & $\mathbf{w}=\mathbf{0 , 7 5}$ & $\mathbf{w}=\mathbf{1 , 0 0}$ \\
\hline ITBR & $-0,49 \%$ & $-2,50 \%$ & - & $6,22 \%$ & $10,08 \%$ \\
\hline ITEU & $42,72 \%$ & $22,95 \%$ & - & $-1,17 \%$ & $10,84 \%$ \\
\hline
\end{tabular}

Tabela (13) Variação de $\mathrm{G}_{\mathrm{w}}$-Beta em relação ao Beta do CAPM (ou $\mathrm{G}_{0,5}$-CAPM)

Observando a tabela anterior, vê-se que ocorreram algumas variações significativas, como é o caso de $G_{1}$-Beta que sofreu uma variação de $12,46 \%$ para o caso do ITBR, e $G_{0}$-Beta que sofreu uma variação de 42,72\% para o ITEU. Vale dizer, entretanto, que para os melhores estimadores do ITBR e ITEU as variações são baixas: -2,5\% e -1,17\%.

\footnotetext{
${ }^{9}$ Adicionalmente, pode ser visto no ANEXO III (Figura 11 ) o gráfico com o comportamento de $\mathrm{G}_{\mathrm{w}}$-Beta ao longo do tempo para os índices ponderados ITBR-P e ITEU-P.
} 
Finalmente, como o modelo $\mathrm{G}_{\mathrm{w}}-\mathrm{CAPM}$ é linear, todas as variações observadas nos valores de Beta apresentados na Tabela (13) refletirão no custo de capital próprio apurado pelo $\mathrm{G}_{\mathrm{w}}-\mathrm{CAPM}$.

\section{2. $\mathrm{G}_{\mathrm{w}}-\mathrm{CAPM}$}

É possível agora calcular o $G_{w}-C A P M$ e o valor real de mercado com base na formulação apresentada no Capítulo anterior.

$\mathrm{Na}$ Figura 7 são apresentados os valores de $G_{w}-C A P M$ entre outubro/2003 e outubro/2005. Tracejado em vermelho está o valor real de mercado para os índices. No cálculo deste valor foi utilizada a média aritmética dos retornos dos 5 anos anteriores. Vale lembrar que estes valores são calculados para cada um dos 25 meses utilizados como base, sendo que a taxa do ativo livre de risco e o prêmio de risco foram convertidos de anuais para mensais.
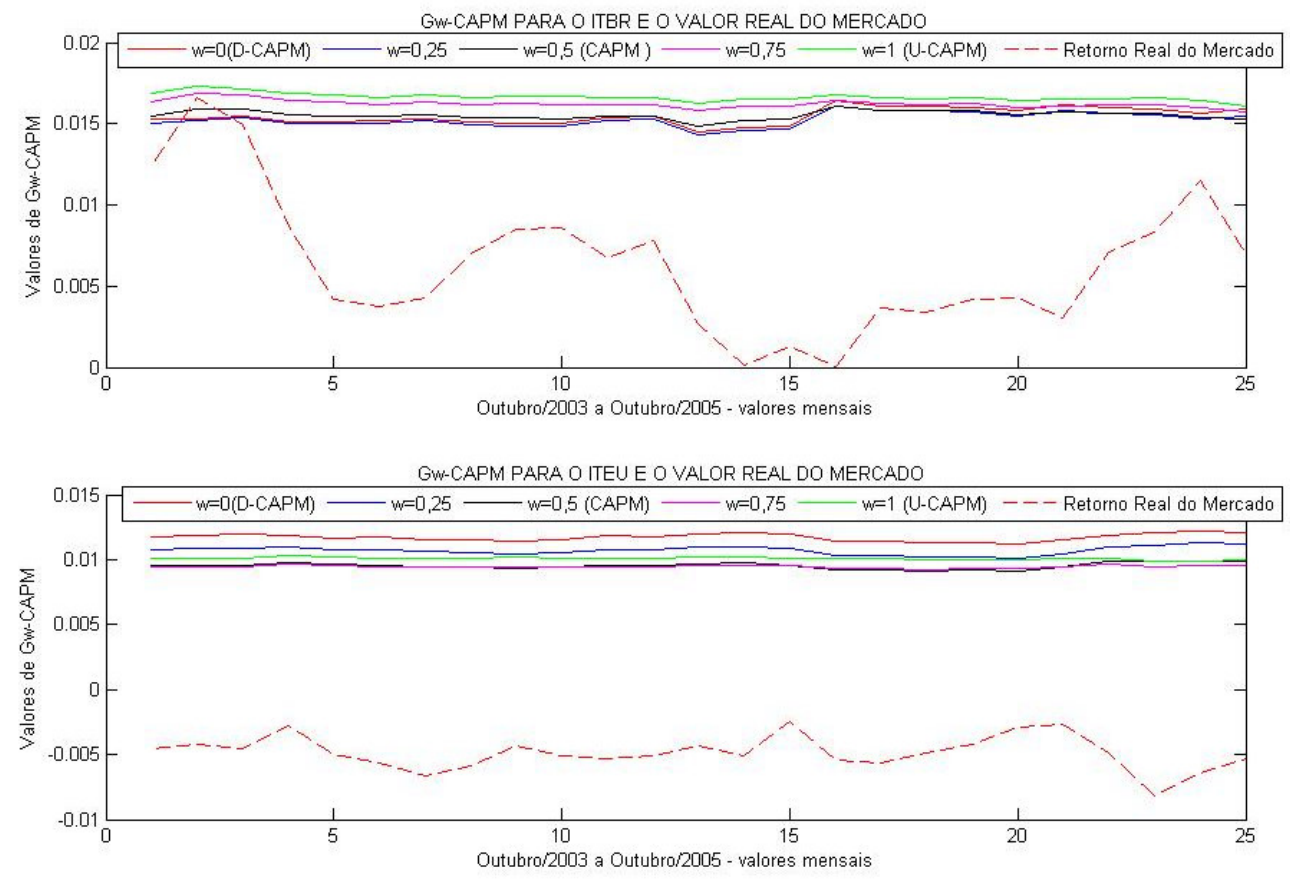

Figura $7-\mathrm{G}_{\mathrm{w}}-\mathrm{CAPM}$ para os índices ITBR e ITEU 
Como se observa na figura anterior, os valores de $G_{w}$-Beta ficaram muito próximos uns dos outros. No entanto, para dirimir quaisquer dúvidas calculou-se a Raiz do Erro Quadrático Médio (REQM) entre cada um dos estimadores e o valor real ao longo dos 25 meses analisados. O resultado para os índices ITBR e ITEU é mostrado na Tabela (14):

\begin{tabular}{cccccc}
\hline & $\mathbf{w}=\mathbf{0 , 0 0}$ & $\mathbf{w}=\mathbf{0 , 2 5}$ & $\mathbf{w}=\mathbf{0 , 5 0}$ & $\mathbf{w}=\mathbf{0 , 7 5}$ & $\mathbf{w}=\mathbf{1 , 0 0}$ \\
\hline ITBR & 0,002056 & 0,001846 & 0,002076 & 0,002697 & 0,003082 \\
\hline ITEU & 0,015549 & 0,014634 & 0,013571 & 0,013514 & 0,014071 \\
\hline
\end{tabular}

Tabela (14) REQM para os índices ITBR e ITEU

Visualizando-se a tabela anterior conclui-se claramente que o melhor estimador para o ITBR é o $\mathrm{G}_{0,25}$-CAPM, enquanto que para o ITEU o melhor é o $\mathrm{G}_{0,75}$-CAPM.

De outro lado, considerando a ponderação dos índices, constata-se que o resultado é mantido, conforme pode ser observado na Tabela (21) e na Tabela (22).

Outra análise de desempenho possível de se fazer é com o índice de Jensen. Na Figura 8 é apresentado o índice para cada um dos valores de w ao longo do tempo. Em destaque na figura está a linha do zero. Quanto mais próximo dessa linha, melhor o estimador. 

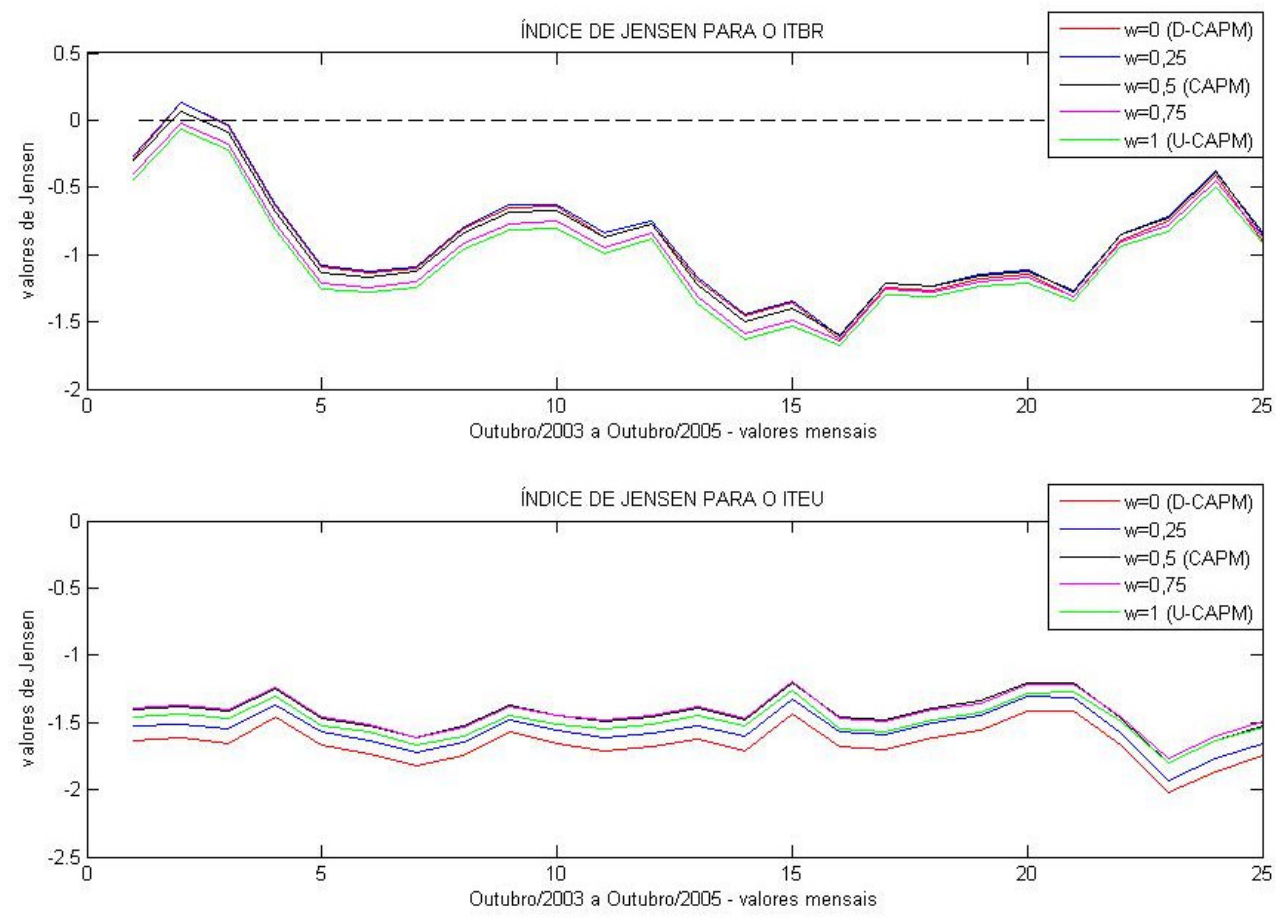

Figura 8 - Valores de Jensen para os índices ITBR e ITEU

Alguns valores ficaram muito próximos. Na Tabela (15), entretanto, percebe-se que o melhor estimador para o ITBR é o $\mathrm{G}_{0,25}$-CAPM, enquanto que para o ITEU é o $\mathrm{G}_{0,75}$-CAPM.

\begin{tabular}{cccccc}
\hline & $\mathrm{w}=0,00$ & $\mathrm{w}=0,25$ & $\mathrm{w}=0,50$ & $\mathrm{w}=0,75$ & $\mathrm{w}=1,00$ \\
\hline ITBR & $-0,800$ & $-0,781$ & $-0,801$ & $-0,868$ & $-0,907$ \\
\hline ITEU & $-1,588$ & $-1,496$ & $-1,390$ & $-1,385$ & $-1,440$ \\
\hline \multicolumn{4}{r}{ Tabela (15) } & Jensen médio para os índices ITBR e ITEU
\end{tabular}

Levando-se em conta a padronização dos índices percebe-se na Tabela (22) que não há alteração na ordem de desempenho dos estimadores.

Finalmente, é possível concluir também que na média o $\mathrm{G}_{\mathrm{w}}-\mathrm{CAPM}$ estimou valores abaixo do esperado para todos os índices. Com relação ao resultado obtido, não há uma conclusão matemática. São todos empíricos, mas estão alinhados com os resultados obtidos 
por ESTRADA $(2002,2003)$ no sentido de que mostram que há outros modelos diferentes do CAPM que são mais plausíveis para o mercado de telecomunicações do Brasil e dos EUA.

\subsection{WACC}

O objetivo deste item é apresentar os resultados obtidos com a metodologia desenvolvida para o caso das telecomunicações no Brasil. Os principais parâmetros utilizados no cálculo do custo de capital e no WACC são apresentados em porcentagem na Tabela (16).

\begin{tabular}{lrrrrr}
\hline & $\mathbf{w}=\mathbf{0 , 0 0}$ & $\mathbf{w}=\mathbf{0 , 2 5}$ & $\mathbf{w}=\mathbf{0 , 5 0}$ & $\mathbf{w}=\mathbf{0 , 7 5}$ & $\mathbf{w}=\mathbf{1 , 0 0}$ \\
\hline Custo de Capital Próprio Nominal & 20,33 & 19,25 & 18,02 & 17,99 & 18,67 \\
\hline Custo de Capital Próprio Real & 17,44 & 16,39 & 15,19 & 15,16 & 15,82 \\
\hline Custo de Capital de Terceiros Nominal & 16,92 & 16,92 & 16,92 & 16,92 & 16,92 \\
\hline Custo de Capital de Terceiros Real & 14,11 & 14,11 & 14,11 & 14,11 & 14,11 \\
\hline Estrutura de Capital adotada & 38,00 & 38,00 & 38,00 & 38,00 & 38,00 \\
\hline Alíquota de Imposto & 34,00 & 34,00 & 34,00 & 34,00 & 34,00 \\
\hline Taxa de Inflação & 2,46 & 2,46 & 2,46 & 2,46 & 2,46 \\
\hline WACC nominal & 16,85 & 16,18 & 15,42 & 15,40 & 15,82 \\
\hline WACC Real & 14,04 & 13,39 & 12,65 & 12,63 & 13,04 \\
\hline
\end{tabular}

Tabela (16) Principais parâmetros utilizados no cálculo do WACC (valores em \%)

A análise desta tabela é possível de dois modos: comparar os resultados obtidos por cada modelo entre si e compará-los com os valores obtidos por outros trabalhos e analisar.

Calculando a variação obtida por cada peso w obtém-se a Tabela (17):

\begin{tabular}{cccccc}
\hline & $\mathbf{w}=\mathbf{0 , 0 0}$ & $\mathbf{w}=\mathbf{0 , 2 5}$ & $\mathbf{w}=\mathbf{0 , 5 0}$ & $\mathbf{w}=\mathbf{0 , 7 5}$ & $\mathbf{w}=\mathbf{1 , 0 0}$ \\
\hline WACC & $14,04 \%$ & $13,39 \%$ & $12,65 \%$ & $12,63 \%$ & $13,04 \%$ \\
\hline Variação & $10,99 \%$ & $5,85 \%$ & - & $-0,16 \%$ & $3,08 \%$
\end{tabular}

Tabela (17) Variação do custo de capital com base no $\mathrm{G}_{\mathrm{w}^{-}} \mathrm{CAPM}$ em relação ao CAPM 
Nesta tabela é possível perceber que há variações significativas, principalmente, com relação ao peso w=0, que gerou um custo de capital 10,99\% acima do gerado pelo CAPM.

Como foram utilizados Beta do mercado dos EUA, era de se esperar que WACC seguisse uma proporcionalidade com $\mathrm{G}_{\mathrm{w}}$-Beta. Assim, percebe-se na tabela anterior que a mesma relação entre os valores de Beta do ITEU se manteve aqui.

Independentemente da relação entre eles, entretanto, o estimador mais indicado para se utilizar é o que apresentar o menor erro com relação ao cálculo do custo de capital próprio. Neste sentido, como o mercado dos EUA foi utilizado como proxy para se chegar a um valor ideal de Beta, o valor mais indicado de WACC a ser utilizado é o fornecido por $\mathrm{w}=0,75$, isto é, $12,63 \%$.

Vale ressaltar ainda que o intuito aqui não é o valor em si, mas se há diferenças significativas entre o valor obtido pelo CAPM $(w=0,50)$ e os demais estimadores. Entretanto, se for considerado o valor em si, ele está um pouco abaixo do que encontrou ACCENTURE e GT (2005), BRAGANÇA et al(2006), UNIBANCO(2006) e BRASCAN(2005), conforme os valores apresentados em porcentagem na Tabela (18):

\begin{tabular}{cccccc}
\hline $\begin{array}{c}\text { Metodologia } \\
\text { desenvolvida }\end{array}$ & $\mathrm{w}=0,00$ & $\mathrm{w}=0,25$ & $\mathrm{w}=0,50$ & $\mathrm{w}=0,75$ & $\mathrm{w}=1,00$ \\
\cline { 2 - 5 } & 14,04 & 13,39 & 12,65 & 12,63 & 13,04 \\
\hline ABN-AMRO (2006) & & 11,95 & \\
\hline BRAGANÇA et \\
al.(2006) & 14,22 & \\
\hline ACCENTURE e GT & & \\
(2005) & & & \\
\hline BRASCAN (2005) & & & \\
\hline Tabela (18) WACC (em \%) obtido por trabalhos acadêmicos e profissionais
\end{tabular}

\footnotetext{
${ }^{10} \mathrm{O}$ trabalho em questão calcula o WACC para as concessionárias brasileiras de telecom individualmente,
} chegando a valores em torno de $15 \%$. 
Portanto, o valor mais indicado para o mercado de telefonia do Brasil (12,63\% a.a.) está um pouco abaixo dos valores encontrados pela maior parte dos trabalhos anteriores. Uma das principais explicações para isso parece ser o valor utilizado para o $G_{w}-$ Beta, que está abaixo de trabalhos como BRAGANÇA et al.(2006) e BRASCAN (2005), implicando um custo de capital próprio menor ${ }^{11}$. ABN-AMRO (2006), no entanto, calculou o custo de capital (WACC) da concessionária de longa distância Embratel Participações e chegou a um valor menor do que todos os encontrados neste trabalho.

Um resumo com cada um dos parâmetros e metodologias adotadas nesta dissertação e em ANEEL (2006) e BRAGANÇA et al. (2006) pode ser visto nos ANEXOS VI e VII.

\footnotetext{
${ }^{11}$ Os parâmetros utilizados na metodologia de ACCENTURE e GT(2005) não são públicos, por isso não é
} possível saber o valor de Beta utilizado. 


\section{Conclusões}

A seguir são apresentadas as conclusões e limitações desta dissertação, bem como algumas sugestões de trabalhos futuros.

\subsection{Conclusões}

A mais importante conclusão está relacionada ao novo modelo apresentado: o $\mathrm{G}_{\mathrm{w}}{ }^{-}$ CAPM. Esse modelo é uma generalização do CAPM que pode estimar melhor o retorno de ações, índices e carteiras de investimento. No caso desta dissertação ele foi aplicado ao setor de telecomunicações, especificamente, na telefonia fixa. Para o caso do índice ITBR o melhor estimador foi o $\mathrm{G}_{0,25}$-CAPM, enquanto que para o ITEU foi o $\mathrm{G}_{0,75^{-}} \mathrm{CAPM}$.

É verdade que, por limitações do próprio mercado de telefonia, o índice adotado é pequeno, composto por apenas três ações. Mas, dentro das limitações existentes, a metodologia conseguiu atender aos objetivos propostos.

Por outro lado, ainda que se tenha encontrado melhores estimadores, perde-se um pouco do grande da simplicidade do CAPM, pois a implementação do $\mathrm{G}_{\mathrm{w}}-\mathrm{CAPM}$ é um pouco mais complexa matematicamente.

Os valores encontrados para o risco do modelo $G_{w}-C A P M\left(G_{w}-\right.$ Beta $)$ aplicado ao ITBR foram mais altos do que os encontrados por BRAGANÇA (2006). O motivo se deve provavelmente à freqüência de observação utilizada pois, ao passo que neste trabalho a frequência foi mensal, naquele foi semanal, diminuindo a volatilidade temporal dos retornos. 
Uma vantagem da metodologia utilizada no $\mathrm{G}_{\mathrm{w}}$-Beta, em relação trabalhos como ANEEL (2006) e BRAGANÇA et al. (2006), foi o fato de calcular uma média ao longo de mais de dois anos. Desta forma é possível verificar se há ou não variações bruscas nos valores de Beta ao longo do tempo, garantindo que o Beta não está refletindo situações pontuais. Aqueles autores consideram um valor pontual para o beta.

Finalmente, com relação aos valores encontrados para o WACC, percebe-se que estão um pouco abaixo dos encontrados por outros trabalhos acadêmicos e profissionais. Isto se deve principalmente aos valores menores utilizados para Beta que refletem diretamente no custo de capital próprio calculado. E a explicação para os valores baixos do Beta é o fato de se ter utilizado como proxy o mercado de telecomunicações dos EUA, que apresenta baixa volatilidade.

\subsection{Limitações}

De uma maneira geral, as principais limitações desta dissertação são: (1) o pequeno período histórico das ações do setor, devido à recente privatização do setor de telecomunicações. Isto implica a inexistência de séries históricas de cotações que sejam longas. O maior período possível se restringe a aproximadamente 7 anos (para ações negociadas na Bolsa de Nova Iorque - NYSE; (2) o fato de se utilizar o mercado dos EUA como referência pois, por mais adaptado que seja, não reflete exatamente a realidade do Brasil; e (3) a falta de parâmetros objetivos para avaliar a melhor metodologia para calcular o WACC para o setor de telecomunicações do Brasil.

Vale dizer para o caso do WACC em específico, entretanto, que os valores obtidos estão próximos dos diversos trabalhos já realizados, tanto acadêmicos quanto profissionais

\subsection{Sugestões para pesquisas futuras}

A generalização do CAPM foi testada no setor de telecomunicações, mas aplica-se perfeitamente a qualquer outra área, bastando para isso compor um índice que represente o mercado que se queira. Desta forma, o modelo pode ser aplicado a qualquer setor, ou mesmo a 
índices que representem o país, como por exemplo, o Morgan Stanley Capital International (MSCI).

Outra possibilidade de pesquisa futura é diminuir o passo de w e analisar o desempenho dos modelos obtidos.

Ou ainda implementar novas formas de comparar o desempenho dos modelos analisados, como por exemplo, através do índice de Sharp, que considera o risco no cálculo do poder de previsão.

Por fim, existe a alternativa também de comparar os modelos variantes do CAPM alterando o período de cálculo do Beta e o período de cálculo do retorno das ações (diário, mensal ou anual) e observar se há mudanças significativas; e desenvolver metodologias para cálculo do custo de capital de negócios específicos da telefonia fixa, como por exemplo, Negócio de Varejo de Telefonia Fixa, Negócio de Varejo de Transmissão de Dados, Negócio de Rede Fixa 


\section{REFERÊNCIAS BIBLIOGRÁFICAS}

ABN-AMRO. Laudo de Avaliação da Embratel Participações. São Paulo, 2006. Disponível em: http://www.unibanco.com.br/arq/publicacao/atc/img/laudo_embrapar_\%20port.pdf. Acesso em 09/06/2006.

ACCENTURE e GUERREIRO TELECONSULT (GT). (Tele)Comunicações 2015: Contribuições para Aperfeiçoamento do Modelo. Apresentação para o evento FUTURECOM. Florianópolis, 2005.

ALEXANDER, I. ESTACHE, I. e OLIVERI, A. A few thing transport regulators should know about risk and the cost of capital. World Bank, 1999.

ALEXANDER, I. MAYER, C. e WEEDS, H. Regulatory structure and risk: an international comparison. World Bank, 1996, mimeo.

AMI. Estimating the cost of capital for fixed and mobile SMP operators in Sweden. Relatório, 2003.

ANATEL. Agência Nacional de Telecomunicações. Regulamento de Separação e Alocação de Contas (RSAC) - aprovado pela Resolução no 396 de 31 de Março de 2005. Brasília, 2005.

ANEEL. Agência Nacional de Energia Elétrica. Metodologia e Cálculo do Custo de Capital das Concessionárias de Distribuição de Energia Elétrica no Brasil. Nota Técnica $\mathrm{N}^{\mathrm{o}}$ 122/2005/SRE/ANEEL. Brasília, 2005.

- Agência Nacional de Energia Elétrica. Metodologia e Cálculo do Custo de Capital. Nota Técnica $n^{\circ}$ 049/2006/SRT/ANEEL. ANEXO DA NOTA TÉCNICA No 051/2006/SRT/ANEEL, Revisão Tarifária Periódica da Concessionária de Transmissão de Energia Elétrica Companhia de Transmissão de Energia Elétrica Paulista (CTEEP). Brasília, 2006. 
Agência Nacional de Energia Elétrica Metodologia e Cálculo da Estrutura Ótima de Capital. Nota Técnica no 048/2006-SRT/ANEEL Brasília, 2006a.

BARBOSA, T. A. e MOTTA, L. F. J. Custo de Capital Próprio em Mercados Emergentes: CAPM X D-CAPM. $5^{\circ}$ Simpósio Brasileiro de Finanças. São Paulo: SBFIN, 2004.

BRAGANÇA, G. F., ROCHA, K. e Camacho, F. A Taxa de Remuneração do Capital e a Nova Regulação das Telecomunicações. Texto para Discussão no 1160. Rio de Janeiro: IPEA, 2006.

BRASCAN. Relatório de Reinício de Cobertura - Telecom, 2005 Disponível em http://www.bancobrascan.com.br/publique/ media/Brascan_Research_Telecom.PDF. Acesso em $09 / 06 / 2006$.

BREALEY, R. A. e MYERS, S. C. Capital Investment and Valuation. New York: Ed. McGrawHill Professional, 2003.

CAMACHO, F. Custo de Capital de Indústrias Reguladas no Brasil. Rio de Janeiro: Revista do BNDES, V. 11, N.21.139-164, 2004.

CARTWRIGHT, P. Interconnecting Costing. Reino Unido: Ed. BWCS, 2001.

COMISSÃO EUROPÉIA. Study by WIK/EAC on Network Interconnection in the Domain of ONP. DGXIII/A/1, Novembro, 1994.

COSTA, O. L. V. e ASSUNÇÃO, H. G. V. Análise de Risco e Retorno em Investimentos Financeiros. São Paulo, Ed. Manole, 2005.

COUTINHO, P. C. e OLIVEIRA, A. O. Determinação da Taxa de Retorno Adequada para Concessionárias de Distribuição de Energia Elétrica no Brasil. Relatório Final. CERME/UnB e FUBRA, 2003. Disponível em: www.unb.br/face/eco/seminarios/sem0603.pdf . Acesso em outubro de 2005.

DAMODARAN, A. Investment valuation. Tools and techniques for determining the value of any assets. Wiley, 2002.

DARST, D. M. The Art of Asset Allocation. New York: Ed. McGraw-Hill Professional, 2003.

ESTRADA, J. Systematic Risk in Emerging Markets: The D-CAPM. Working Paper. Barcelona: IESE Business School, 2002 Disponível em: http://web.iese.edu/jestrada/Research.html. Acesso em outubro de 2005. 
- Mean-Semivariance Behavior (II): The D-CAPM. Working Paper. Barcelona: IESE

Business School, 2003 Disponível em: http://web.iese.edu/jestrada/Research.html. Acesso em outubro de 2005.

GIBSON, R. C. Asset Allocation: Balancing Financial Risk. Nova Iorque: Ed. McGraw-Hill Professional, 2000.

GORDON, M. The investment, financing, and valuation of the corporation. Irwin, Homewood, IL, 1962.

HARKER, P. T. e ZENIOS, S. A. Performance of Financial Institutions: Efficiency, Innovation, Regulation. Reino Unido: Ed. Cambridge University Press, Cambridge, 2000.

KAYO, E. K. A Estrutura de Capital e o Risco das Empresas Tangivel e Intangivel-Intensas: Uma Contribuição ao Estudo da Valoração de Empresas. Faculdade de Economia e Administração, Universidade de São Paulo, 2002.

LINTNER, J. Security prices, risk, and maximal gains from diversification. Journal of Finance, 20, 587-616, 1965.

LUENBERGER, D. G. Investment Science. New York: Ed. Oxford University Press, 1998.

MARKOWITZ, H. M. Porffolio Selection: Efficient Diversification of Investments. Nova York: John Wiley, 1959.

PRATT, S. P. Cost of Capital: estimation and applications. New York: John Wiley \& Sons, 1998.

ROSS, S. A. WESTERFIELD, R. W. e JAFFE, J. F. Administração Financeira. Trad. Antonio Zorato Sanvicente. São Paulo: Ed. Atlas, 1995.

. The arbitrage theory of capital asset pricing. Journal of Economic Theory, v. 13. p. 341-360, 1976.

SHARPE, W. The capital asset prices: $A$ theory of market equilibrium under conditions of risk. Journal of Finance, 19, 425-442, 1964.

VALLETTI, Tommaso M. ROBIN, M. Competition in communication networks: Pricing and regulation. Oxford Review of Economic Policy. 17, 389-415, 2001. 


\section{GLOSSÁRIO}

Acesso local: rede que interliga uma central de comutação ao usuário final de telecomunicações.

Alavancagem: relação entre a dívida de longo-prazo de uma empresa e o capital empregado, composto do capital próprio e do capital de terceiros.

ANEEL: Agência Nacional de Energia Elétrica.

Beta: parâmetro utilizado no modelo CAPM para quantificar o risco de uma ação ou carteira de investimento.

Beta Alavancado: Beta calculado com base nas ações de mercado de uma determinada operadora. Reflete a estrutura de capital da empresa, isto é, quanto mais alavancagem, maior o reflexo no valor de Beta.

Beta Desalavancado: Beta calculado com base no Beta alavancado através da fórmula apresentada na EQ. (23). Esse Beta simula a situação de uma empresa que empresa teria apenas capital próprio empregado. Logo o valor de Beta Desalavancado é sempre menor ou igual ao Alavancado.

Beta Realavancado: Beta calculado com base no Beta realavancado através da fórmula apresentada na EQ. (25). É um ajuste feito para contornar o problema de falta de maturidade do mercado financeiro local. 
Custo de Capital Próprio: é o retorno requerido pelo acionista sobre o capital investido. O cálculo considera que um determinado ativo deve pagar ao investidor o custo de oportunidade acrescido de um prêmio de risco (ABN-AMRO, 2006).

Custo da Dívida: é uma medida do valor pago pelo capital provindo de terceiros, sob a forma de empréstimos, financiamentos, captações no mercado, entre outros (ABN-AMRO, 2006);

Custo Médio Ponderado de Capital ou "Weighted Average Cost of Capital" (WACC): é uma medida do custo de capital de uma companhia. O WACC é determinado pela média ponderada, com base na estrutura de capital de longo prazo, dos custos da dívida e de capital próprio e está diretamente relacionado ao risco associado aos futuros fluxos de caixa (ABN-AMRO, 2006);

Duration: é um conceito financeiro moderno que representa a duração média ponderada dos fluxos de caixa de um ativo ou carteira (ANEEL, 2006);

Desagregação de rede (“unbundling”): termo que designa o aluguel de uma rede de telecomunicações própria para outra prestadora de serviços de telecomunicações;

Emerging Markets Bonds Index (EMBI): índice que equivale ao retorno total de títulos denominados em dólar relativos à renegociação da dívida externa brasileira (Bradies) nos mercados emergentes e que satisfazem a uma série de critérios de liquidez (BRAGANÇA et al., 2006);

Emerging Markets Bonds Index (EMBI+): índice semelhante ao EMBI mas que relaxa alguns critérios de liquidez e incorpora mais instrumentos a sua composição. Recomenda-se com bastante consistência a utilização do índice EMBI+ (BRAGANÇA et al., 2006);

EQM : Erro Quadrático Médio;

Estrutura de Capital: relação entre a dívida de longo-prazo de uma empresa (D) e o capital empregado (capital próprio e capital de terceiros - D+E), representado da seguinte forma: $\mathrm{D} /(\mathrm{D}+\mathrm{E})$. Essa relação é importante para observar o nível de endividamento da empresa. No caso parâmetro Beta, quanto maior a estrutura de capital, maior será o seu valor; 
Interconexão: Ligação entre redes de telecomunicações funcionalmente compatíveis, de modo que os usuários de serviços de uma das redes possam comunicar-se com usuários de serviço de outra ou acessar serviços nelas disponíveis. A interconexão é cobrada de uma operadora para outra;

IPCA: Índice Nacional de Preços ao Consumidor Amplo;

ITBR: Índice de Telecomunicações do Brasil que foi montado para representar o mercado local de telefonia fixa do Brasil.

ITEU: Índice de Telecomunicações dos EUA que foi montado para representar o mercado de telefonia fixa dos EUA.

LRIC: Long Run Incremental Cost ou custo incremental de longo prazo.

Maturidade: data média em que o valor principal de um título é recuperado totalmente.

PMS: Poder de Mercado Significativo. Posição que possibilita influenciar de forma significativa as condições do mercado relevante, assim considerada pela ANATEL;

Price Cap: modelo de regulação em que o regulador ajusta o preço das tarifas com base na inflação (p. ex. IGP-DI, IPCA, etc.) e desconta uma taxa de produtividade, chamada fator X. Este fator de redução visa estimular a redução de custos e o aumento de eficiência.

Regulação por Incentivos: tipo de regulação econômica utilizada pelos reguladores para incentivar o aumento de eficiência com redução de custos. Baseia-se no estabelecimento de um valor máximo para reajuste de tarifas de um conjunto de produtos. O modelo mais conhecido deste tipo de regulação é o Price-Cap ou Preço-teto.

Regulação por Taxa de Retorno: tipo de regulação econômica em que o regulador estipula uma taxa de retorno máxima a ser aplicada ao capital empregado. É um tipo de regulação que não estimula a redução de custo.

REQM: Raiz do Erro Quadrático Médio;

Risco de negócio: grau de incerteza em relação à projeção do retorno sobre o ativo total inerente ao negócio, que não pode ser eliminado por diversificação (ANEEL, 2006). Risco associado ao negócio em si que não pode ser diversificável. É o risco no caso em que todo o capital empregado é próprio. Em outras palavras é o risco sistemático; 
Risco financeiro: risco adicional devido ao uso de capital de terceiros no financiamento de projetos, isto é, o risco adicionado ao projeto devido à alavancagem financeira;

Setores regulados: áreas da administração pública que estão confiadas às agências reguladoras que, em teoria, são órgãos independentes administrativa e financeiramente, tais como energia elétrica, regulado pela ANEEL, petróleo e gás natural, regulado pela ANP, e telecomunicações, regulado pela ANATEL, entre outros;

S\&P 500: índice de mercado composto pelas 500 maiores empresas dos EUA.

TJLP: Taxa de juros de Longo Prazo (valor real); é a taxa de juros cobrada pelo empréstimos do BNDES.

TNX: símbolo utilizado na Bolsa de Nova Iorque (NYSE) para representar o Título do Tesouro dos EUA com vencimento em 10 anos (USTB10), e duration de aproximadamente 8 anos;

USTB10: Bônus do Tesouro dos EUA com vencimento de 10 anos. Na bolsa de Nova Iorque (NYSE) ele é representado pelo símbolo TNX; 


\section{ANEXo I - PreÇOS NORMALIZADOS DAS AÇÕES E ÍNDICES}

Preços das ações que compõem ITBR e ITEU (valor inicial normalizado em 1000 pontos)

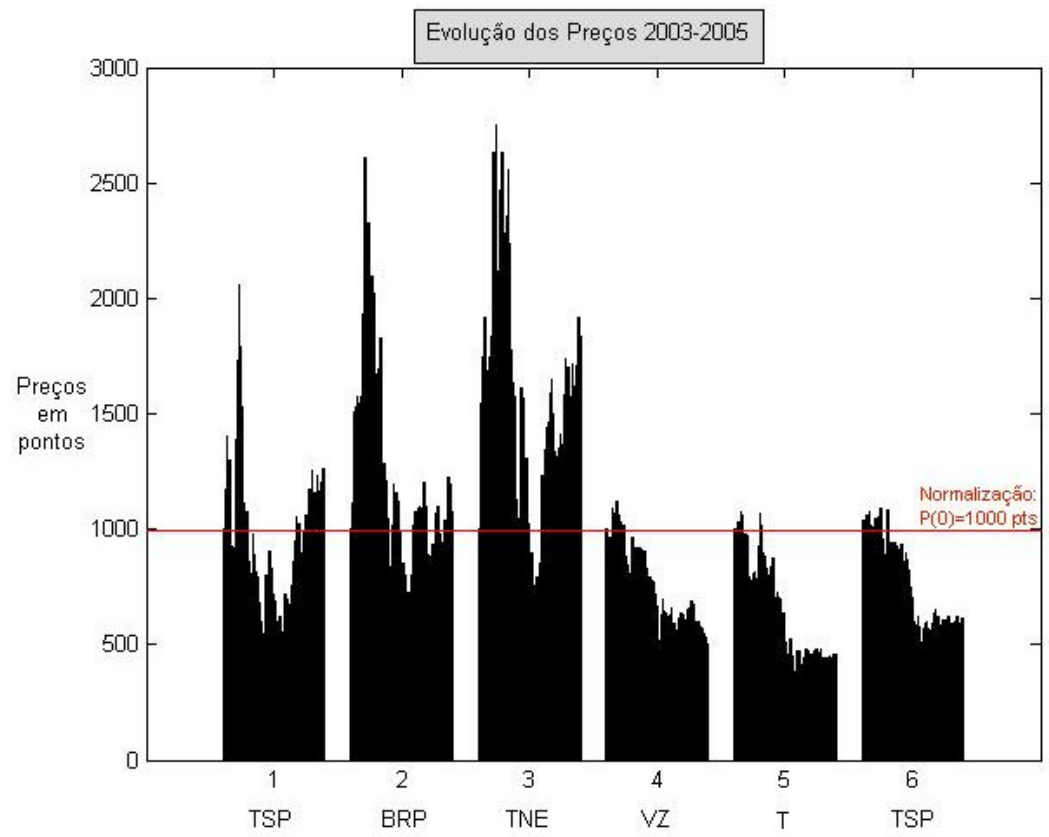

Figura 9 - Preços de cada uma das ações que compõem os índices ITBR e ITEU

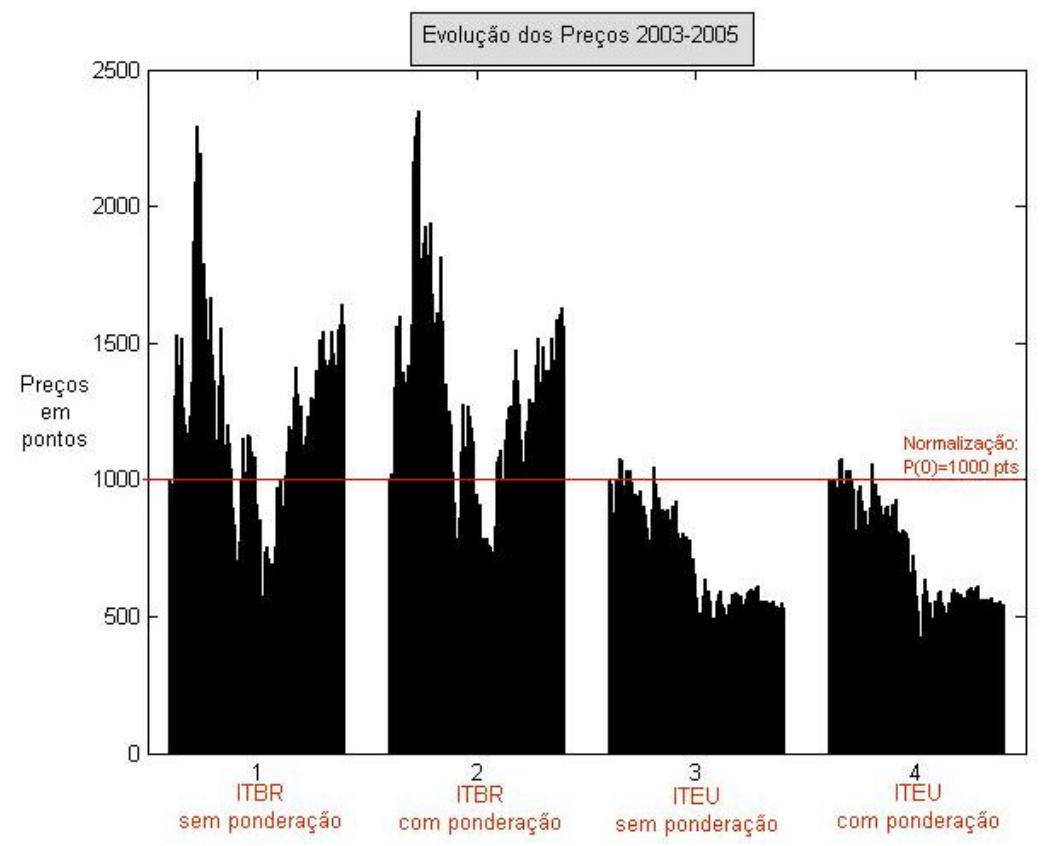

Figura 10 - Cotação dos índices ITBR e ITEU 
ANEXO II - MODELOS EUROPEUS UTILIZADOS PARA O CÁLCULO DO CUSTO DE CAPITAL PRÓPRIO

\begin{tabular}{cc}
\hline Países & Diferenciação \\
\hline Alemanha & CAPM \\
Áustria & CAPM \\
Bélgica & CAPM \\
Dinamarca & CAPM \\
Espanha & CAPM \\
Finlândia & Diversos \\
França & CAPM \\
Grécia & CAPM \\
Holanda & CAPM \\
Irlanda & CAPM \\
Portugal & CAPM \\
Reino Unido & CAPM \\
Suécia & CAPM \\
\hline Fonte: AMI (2003, em BRAGANÇA et al., 2006)
\end{tabular}




\section{ANEXO III - DIVERSAS FIGURAS PARA OS ÍNDICES PONDERADOS ITBR-P E ITEU-P}
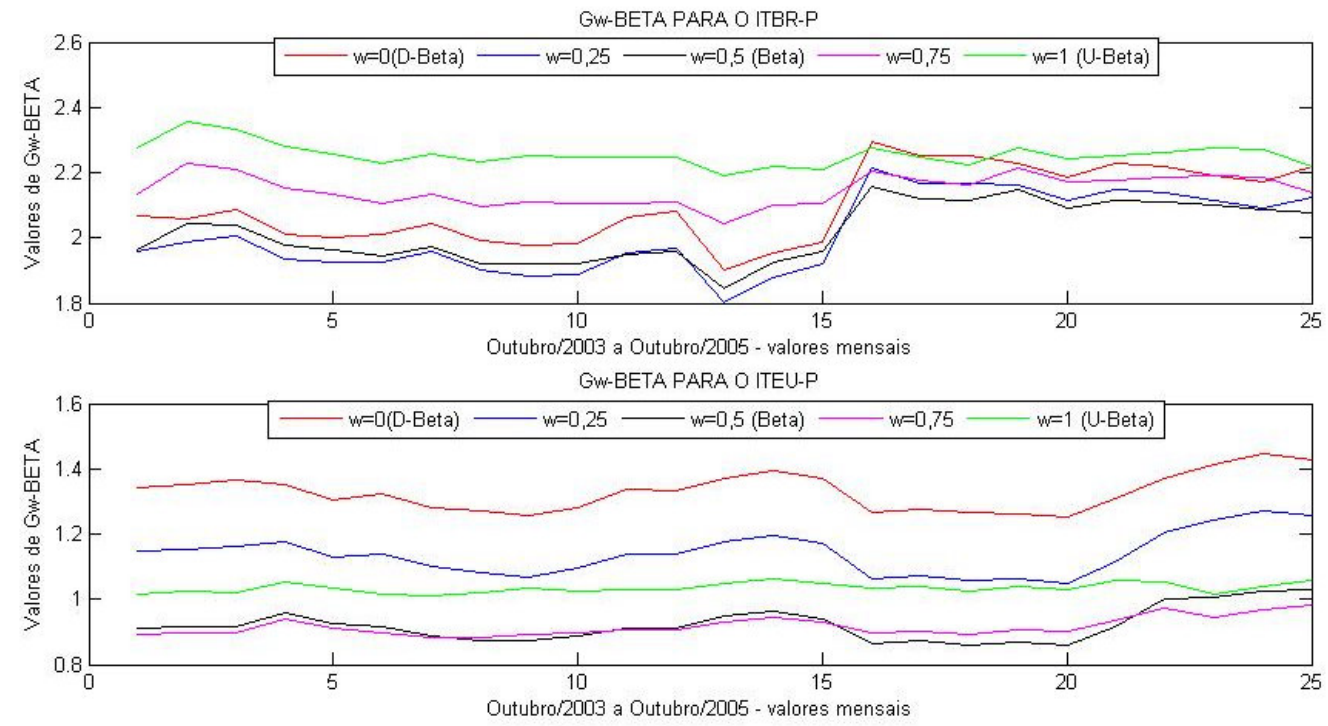

Figura $11-\mathrm{G}_{\mathrm{w}}-$ Beta para os índices ponderados ITBR-P e ITEU-P
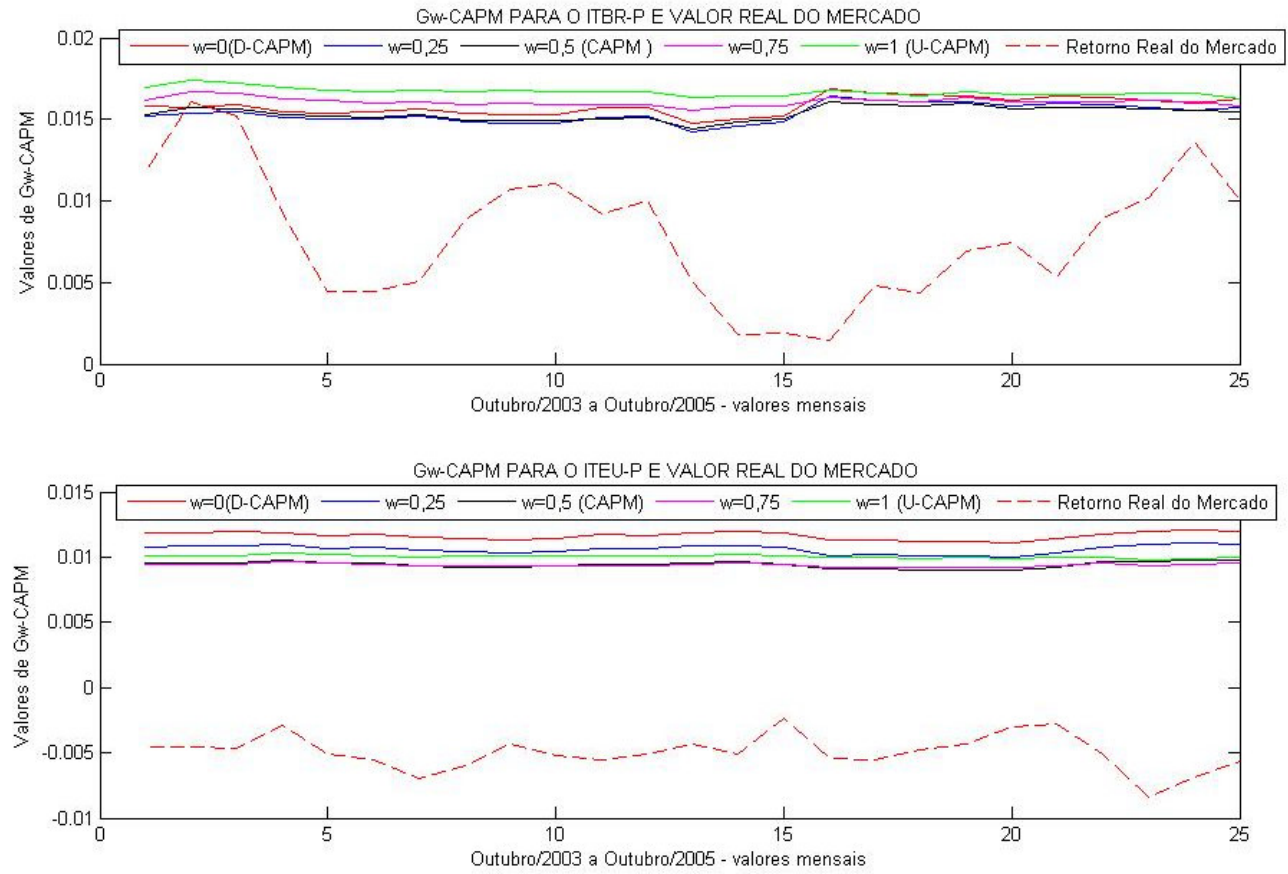

Figura 12 - Valores de $\mathrm{G}_{\mathrm{w}}$-CAPM para os índices ponderados ITBR-P e ITEU-P 

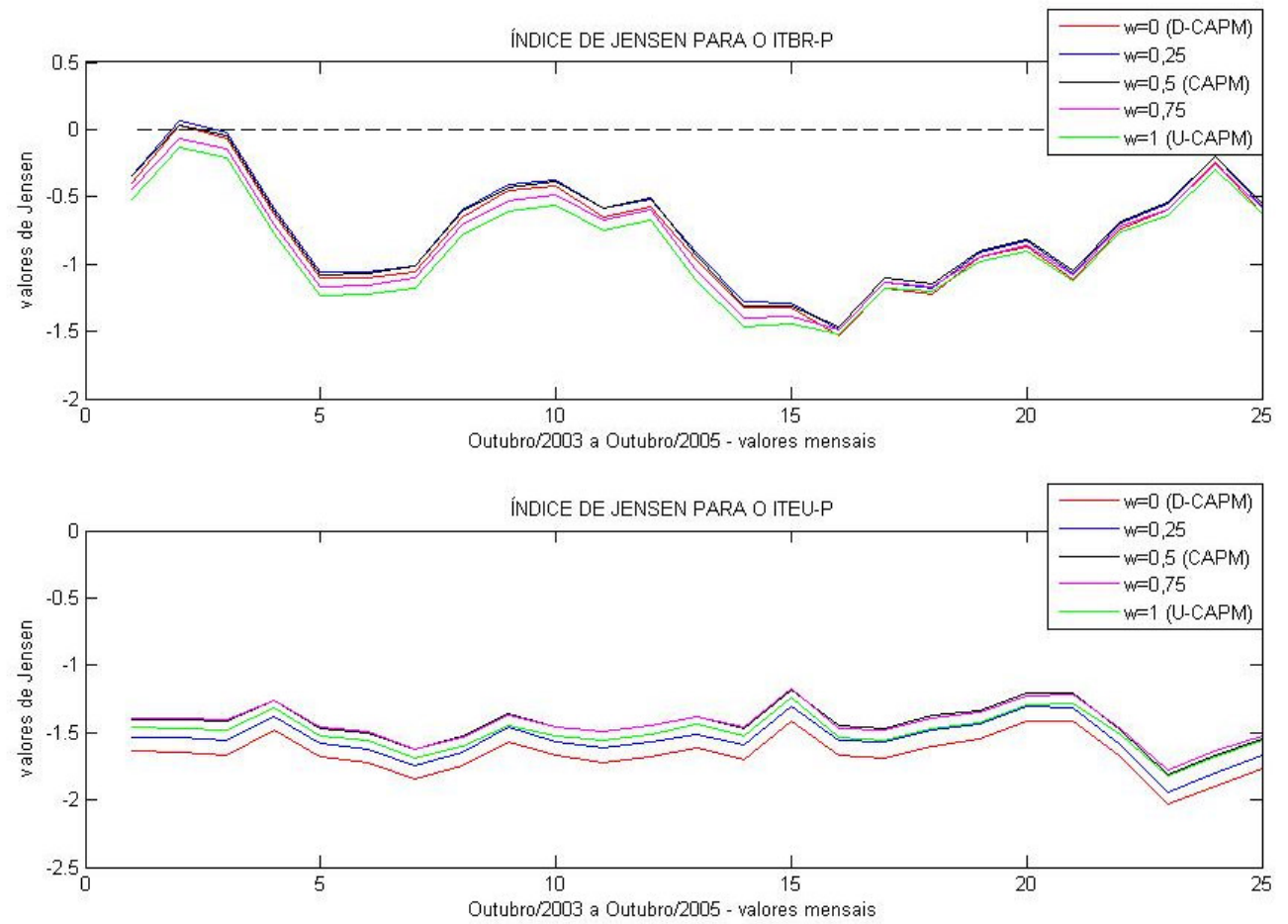

Figura 13 - Valores de Jensen para os índices ponderados ITBR-P e ITEU-P 


\section{ANEXo IV - VALORES MÉdIOS DE $\mathrm{G}_{\mathrm{w}}$-BETA PARA CADA UMA DAS AÇÕES}

\begin{tabular}{cccccc}
\hline & $\mathbf{w}=\mathbf{0 , 0 0}$ & $\mathbf{w}=\mathbf{0 , 2 5}$ & $\mathbf{w}=\mathbf{0 , 5 0}$ & $\mathbf{w}=\mathbf{0 , 7 5}$ & $\mathbf{w}=\mathbf{1 , 0 0}$ \\
\hline TSP & 2,208 & 2,007 & 1,866 & 1,977 & 2,153 \\
\hline BRP & 2,083 & 1,979 & 1,946 & 2,053 & 2,162 \\
\hline TNE & 2,329 & 2,264 & 2,318 & 2,486 & 2,597 \\
\hline Tabela (19) & Valores médios de $\mathrm{G}_{\mathbf{w}}$-Beta para ações TSP, BRP e TNE
\end{tabular}

\begin{tabular}{cccccc}
\hline & $\mathbf{w}=\mathbf{0 , 0 0}$ & $\mathbf{w}=\mathbf{0 , 2 5}$ & $\mathbf{w}=\mathbf{0 , 5 0}$ & $\mathbf{w}=\mathbf{0 , 7 5}$ & $\mathbf{w}=\mathbf{1 , 0 0}$ \\
\hline VZ & 1,448 & 1,237 & 0,955 & 0,895 & 1,004 \\
\hline ATT & 1,281 & 1,029 & 0,797 & 0,862 & 1,048 \\
\hline BLS & 1,512 & 1,319 & 1,070 & 1,028 & 1,132 \\
\hline Tabela (20) & Valores médios de $\mathrm{G}_{\mathbf{w}}$-Beta para ações VZ, AT'T e BLS
\end{tabular}




\section{ANEXO V - REQM E JENSEN PARA OS ÍNDICES PONDERADOS ITBR-P E ITEU-P}

\begin{tabular}{cccccc}
\hline REQM & $\mathbf{w}=\mathbf{0 , 0 0}$ & $\mathbf{w}=\mathbf{0 , 2 5}$ & $\mathbf{w}=\mathbf{0 , 5 0}$ & $\mathbf{w}=\mathbf{0 , 7 5}$ & $\mathbf{w}=\mathbf{1 , 0 0}$ \\
\hline ITBR-P & 0,00298 & 0,00256 & 0,00256 & 0,00319 & 0,00372 \\
\hline ITEU-P & 0,01546 & 0,01451 & 0,01345 & 0,01342 & 0,01400 \\
\hline Tabela (21) & REQM para os índices ponderados ITBR-P e ITEU-P
\end{tabular}

\begin{tabular}{cccccc}
\hline Jensen & $\mathbf{w}=\mathbf{0 , 0 0}$ & $\mathbf{w}=\mathbf{0 , 2 5}$ & $\mathbf{w}=\mathbf{0 , 5 0}$ & $\mathbf{w}=\mathbf{0 , 7 5}$ & $\mathbf{w}=\mathbf{1 , 0 0}$ \\
\hline ITBR-P & $-0,6825$ & $-0,6407$ & $-0,6424$ & $-0,7065$ & $-0,7601$ \\
\hline ITEU-P & $-1,5919$ & $-1,4980$ & $-1,3911$ & $-1,3883$ & $-1,4467$ \\
\hline Tabela (22) & Jensen para os índices ponderados ITBR-P e ITEU-P
\end{tabular}

Como se observa na Tabela (21), os valores de REQM para o ITBR-P são iguais quando se utiliza o $\mathrm{G}_{0,25}$-CAPM e o $\mathrm{G}_{0,50}$-CAPM. Entretanto, analisando a Tabela (22) percebese que o melhor modelo é o $\mathrm{G}_{0,25}$-CAPM, que apresenta um valor mais próximo de zero. 


\section{ANEXo VI - Custo de CAPITAL dAS Diversas metodologias}

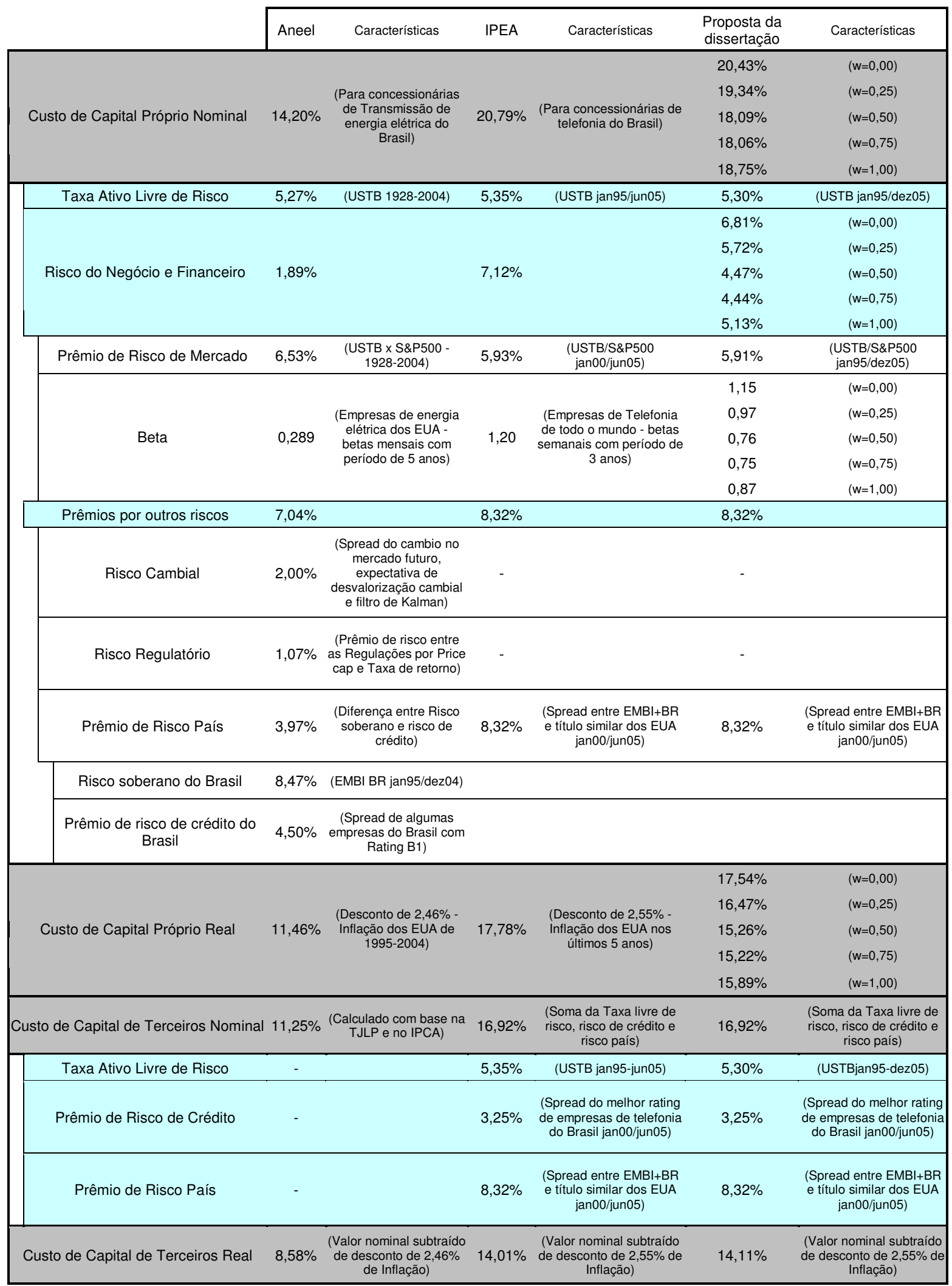




\section{ANEXO VII - OUTROS PARÂMETROS UTILIZADOS NO CÁLCULO DO WACC}

\begin{tabular}{|c|c|c|c|c|c|c|}
\hline & Aneel & Características & IPEA & Características & $\begin{array}{l}\text { Proposta da } \\
\text { dissertação }\end{array}$ & Características \\
\hline Estrutura de Capital Adotada & $55 \%$ & $\begin{array}{c}\text { (Metodologia para } \\
\text { estrutura de capital } \\
\text { ótima) }\end{array}$ & $38 \%$ & $\begin{array}{l}\text { (Média da estrutura de } \\
\text { capital das diversas } \\
\text { empresas do Brasil) }\end{array}$ & $38 \%$ & $\begin{array}{l}\text { (Média da estrutura de } \\
\text { capital das diversas } \\
\text { emrpesas do Brasil) }\end{array}$ \\
\hline Alíquota de Imposto & $34 \%$ & & $34 \%$ & & $34 \%$ & \\
\hline Inflação dos EUA & $2,46 \%$ & (Média 1995-2004) & $2,55 \%$ & (Média últimos 5 anos) & $2,46 \%$ & (Média1995-2004) \\
\hline \multirow{5}{*}{ WACC Nominal } & \multirow{5}{*}{$11,46 \%$} & & \multirow{5}{*}{$17,13 \%$} & & $16,91 \%$ & $(w=0,00)$ \\
\hline & & & & & $16,23 \%$ & $(w=0,25)$ \\
\hline & & & & & $15,46 \%$ & $(w=0,50)$ \\
\hline & & & & & $15,44 \%$ & $(w=0,75)$ \\
\hline & & & & & $15,87 \%$ & $(w=1,00)$ \\
\hline \multirow{5}{*}{ WACC Real } & \multirow{5}{*}{$8,27 \%$} & & \multirow{5}{*}{$14,22 \%$} & & $14,10 \%$ & $(w=0,00)$ \\
\hline & & & & & $13,44 \%$ & $(w=0,25)$ \\
\hline & & & & & $12,69 \%$ & $(w=0,50)$ \\
\hline & & & & & $12,67 \%$ & $(w=0,75)$ \\
\hline & & & & & $13,08 \%$ & $(w=1,00)$ \\
\hline
\end{tabular}




\section{ANEXo VIII - TAXA DE DESCONTO DA INFLAÇÃo}

$\mathrm{Na}$ transformação de uma taxa nominal para o valor real foi utilizada a equação abaixo:

EQ. (35)

$$
X_{\text {real }}=\frac{X_{n o \min a l}-1}{1+r}
$$

sendo

$\mathrm{X}_{\text {real }}=$ taxa real;

$\mathrm{X}_{\text {nominal }}=$ taxa nominal;

$\mathrm{r}=$ taxa de inflação média utilizada. 
ANEXo IX - COMPOSIÇÃo DE ITEU E ITEU-P

\begin{tabular}{cccc}
\hline Símbolo & Empresa & Composição de ITEU & Composição de ITEU-P \\
\hline VZ & Verizon & 0,33 & 0,39 \\
\hline ATT & AT\&T & 0,33 & 0,38 \\
\hline BLS & Bell South & 0,33 & 0,23 \\
\hline
\end{tabular}

Tabela (23) Características das ações e índices utilizados no ITEU e ITEU-P 